\title{
Overview of the Components of Cardiac Metabolism
}

\author{
Elizabeth A. Hausner, Susan A. Elmore, and Xi Yang \\ United States Food and Drug Administration, Center for Drug Evaluation and Research, Silver Spring, Maryland (E.A.H., X.Y.); \\ and National Toxicology Program, National Institute of Environmental Health Sciences, Research Triangle Park, \\ North Carolina (S.A.E.)
}

Received January 30, 2019; accepted March 26, 2019

\section{ABSTRACT}

Metabolism in organs other than the liver and kidneys may play a significant role in how a specific organ responds to chemicals. The heart has metabolic capability for energy production and homeostasis. This homeostatic machinery can also process xenobiotics. Cardiac metabolism includes the expression of numerous organic anion transporters, organic cation transporters, organic carnitine (zwitterion) transporters, and ATP-binding cassette transporters. Expression and distribution of the transporters within the heart may vary, depending on the patient's age, disease, endocrine status, and various other factors. Several cytochrome P450 (P450) enzyme classes have been identified within the heart. The P450 hydroxylases and epoxygenases within the heart produce hydroxyeicosatetraneoic acids and epoxyeicosatrienoic acids, metabolites of arachidonic acid, which are critical in regulating homeostatic processes of the heart. The susceptibility of the cardiac P450 system to induction and inhibition from exogenous materials is an area of expanding knowledge, as are the metabolic processes of glucuronidation and sulfation in the heart. The susceptibility of various transcription factors and signaling pathways of the heart to disruption by xenobiotics is not fully characterized but is an area with implications for disruption of normal postnatal development, as well as modulation of adult cardiac health. There are knowledge gaps in the timelines of physiologic maturation and deterioration of cardiac metabolism. Cross-species characterization of cardiac-specific metabolism is needed for nonclinical work of optimum translational value to predict possible adverse effects, identify sensitive developmental windows for the design and conduct of informative nonclinical and clinical studies, and explore the possibilities of organ-specific therapeutics.

\section{Introduction}

The extensive and expanding volume of information on the components of hepatic metabolism is now accompanied by a new perspective on extrahepatic drug metabolism. In addition to drug metabolism in the kidneys, lungs, and gastrointestinal tract, it is recognized that other organs, including the heart, have the capacity for xenobiotic metabolism, as well as the extensive processes involved in the endobiotic transformations necessary for homeostasis (Stegeman et al., 1982; Wu et al., 1997; Gervasini et al., 2004; Pavek and Dvorak, 2008). Although this is a minor portion of overall systemic metabolism, there is potential for local drug metabolism to be an important factor in both desired pharmacology and unwanted cardiotoxicity. This factor is especially important when considering populations that may be more vulnerable to adverse drug effects, such as children or elderly patients.

This research was supported in part by the Intramural Research Program of the National Institutes of Health (NIH) National Institute of Environmental Health Sciences (NIEHS).

https://doi.org/10.1124/dmd.119.086611.
Tremendous efforts have been devoted to characterizing the physiologic differences between infants, children, and adults, but much remains to be investigated. Incomplete understanding of pediatric development may lead to significant difficulties in providing safe and effective medications for children. Simply extrapolating doses or systemic drug exposures for children based on the adult clinical experience may lead to either lack of efficacy or increased risk from dosing that is inappropriate for the pediatric physiology. Whereas dose extrapolation may include consideration of differences in maturation and metabolism between the two populations, it may not be possible to estimate the effects on developing body systems, especially when some effects may not become apparent for years or even decades after drug exposure.

Postnatal development of the heart encompasses changes in structure, proportions of the components, mechanisms of growth, metabolism for energy generation, local innervation, central nervous system regulatory pathways, local receptor density and distribution, local transmitter synthesis and storage, ion channel development, electrical conduction development, and the interface with renal (maturation of renin-angiotensin-aldosterone axis) and endocrine development (involvement of the thyroid axis and insulin in cardiac maturation).

ABBREVIATIONS: AA, arachidonic acid; ABC, ATP-binding cassette; AJ, adherens junction; AOX, aldehyde oxidase; Cx, connexin; EET, epoxyeicosatrienoic acid; GLUT, facilitative glucose transporter; HETE, hydroxyeicosatrienoic acid; ID, intercalated disk; MRP, multidrug resistance protein; NAT, N-acetyltransferases; OAT, organic anion transporter; OATP, organic anion transporting polypeptide; OCT, organic cation transporter; OCTN, organic carnitine transporter; P450, cytochrome P450; PANX, pannexin; P-gp, P-glycoprotein; SGLT, sodium-glucose cotransporter; SULT, sulfotransferase; TJ, tight junction; ZO-1, zonula occludens-1. 
The same nexus of development that integrates signaling pathways from spatially separated organs primarily processes endogenous substances such as hormones, fatty acids, glucose, prostaglandins, and other substances for homeostasis. The receptors, transporters, sensors, and enzymes of metabolism may be developmentally regulated, and they may in turn help to coordinate postnatal development by their roles in communication between organ systems.

At any age, variability of expression and/or function of transporters and metabolic enzyme systems may contribute to observed variability of response to a therapeutic agent. Another important factor is the role of the heart in several endocrine axes. The heart demonstrates endocrine function in the regulation of blood pressure and volume involving distant communication with kidneys, adrenal glands, and vascular smooth muscle cells through the renin-angiotensinaldosterone system, as well as cardiac-initiated signals from the natriuretic peptides and endogenous neural signals (Brownsey et al., 1997; McGrath et al., 2005; Ogawa and de Bold, 2014). Insulin and thyroid hormones have been indicated in the postnatal development of the heart, as well as having effects on enzymes, transporters, and protein expression throughout life (Krüger et al., 2008; BarretoChaves et al., 2010; Jonker and Louey, 2016; Ock et al., 2016). Many of the molecules involved in metabolism within the heart appear to work in concert with protein partners, a phenomenon that appears to create and maintain coordination within and between cells (Brownsey et al., 1997; Meens et al., 2015). The insulin receptor is one example of a coordination of signaling proteins, with the receptor producing a localized cardiac effect (Brownsey et al., 1997). Another example is the role of the thyroid in most aspects of cardiovascular function. Thyroid hormone effects are mediated directly by thyroid hormone receptors in the heart and indirectly via factors including the autonomic nervous system, the renin-angiotensin-aldosterone system, and renal function. The phosphorylation/activation of phosphoinositol 3-kinase, protein kinase $\mathrm{B}$, and mammalian target of rapamycin are mediators of thyroid hormone involvement in cardiomyocyte protection, growth, and maturation, including developmental protein isoform shifts [reviewed in Kuzman et al. (2005), Kenessey and Ojamaa (2006), Krüger et al. (2008), Dillmann (2010), Chattergoon et al. (2012), and Grais and Sowers (2014)]. The multitude of proteins within the heart and the developmentally regulated shifts that occur throughout life make the morphologic status of the heart a component of the metabolic milieu.

In drug development, the biologic fate of a xenobiotic is determined by absorption, distribution, metabolism, and excretions, topics we address in this review based on the current literature findings. In addition to this paradigm, many factors need to be considered in choosing an animal species for nonclinical studies in cardiac physiology and pharmacology. The relevance of those results in guiding clinical studies or drug development depends on knowledge of the similarities and differences across species. Detailed understanding of cardiac metabolism offers the possibility of targeted, organ- specific therapy or, conversely, avoiding cardiac-specific toxicology, which includes both direct adverse effects of a therapeutic effect as well as indirect effects caused by disruption of metabolism needed for homeostasis or normal development. Thus, knowledge of cardiac metabolism has the potential to improve therapeutic safety for both children and adults. Finally, nonclinical studies conducted with a clear understanding of cardiac metabolism in different species will enhance the translational value of such work supporting the standards of the three Rs: reduce, refine, and replace. The focus of this manuscript is compilation of the current understanding of metabolism endogenous to the heart. Part of this endeavor includes identification of data gaps.

\section{Absorption}

Endothelium. Any systemically available xenobiotic and associated metabolites will circulate in the blood to some extent and pass through at least the right atrium and right ventricle. The drugs not absorbed in the lungs, as well as the metabolites generated there and released into circulation, will pass through the left atrium and left ventricle. Absorption of xenobiotics into the heart will be regulated by the same principles that apply elsewhere, such as the cellular structure of the heart; the presence of transporters, receptors, and enzymes; the functional or maturational state of the heart; and the physicochemical properties of the drug. Two important considerations for cardiac metabolism are 1) the role of the endothelial junctions and tight junctions in intracellular signaling pathways and 2) the role of developmentally regulated protein isoforms in endothelial regulation of permeability.

The endothelium is one of the controlling factors for the movement of plasma components to the interstitium, with numerous factors contributing to the efficacy as a selective barrier. That is, although there will be molecular and time-frame variations across species, the shared, nonspecies-specific features of the absorption barrier include characteristics of the endothelial cells themselves, the interendothelial junctions, transport pathways, and their role in myocardial metabolism (Bazzoni and Dejana, 2004). Endothelial cells in general, across species, are heterogeneous populations, varying with location. Within the heart, the different groups of endothelial cells include those of the endocardium, coronary arteries and veins (not discussed here as this is beyond the scope of this manuscript), and myocardial capillaries.

Endothelial cells of the endocardium are larger than endothelial cells of other cardiac locations, with increased surface area composed of microvilli. The intercellular clefts are deeper, more tortuous, have more gap junctions, and fewer vesicles compared with the endothelial cells of the myocardial capillaries. As described by Katz et al. (2013), Poiseulle's law regulates molecular movement through the endothelium. Hydraulic conductivity is dependent on fluid viscosity and pore radius of the permeability pathways. The permeability pathways include the small pores $(4 \mathrm{~nm})$ of capillary endothelium, large pores (25-80 nm) occurring between endothelial cells, endothelial vesicles, and transendothelial pores (Katz et al., 2013).

The capillaries of the myocardium have continuous endothelium with tight junctions between the endothelial cells and close contact with cardiomyocytes. There is a ratio of three myocardial endothelial cells to one cardiomyocyte, separated by $1 \mu \mathrm{m}$. The high proportion of endothelial cells to cardiomyocytes and close apposition facilitates transfer of blood-borne substances (Hsieh et al., 2006).

In addition to the endothelial cells, other components contribute to selective passage of molecules to and through the heart. These components include the tight junctions (TJ), adherens junctions (AJ), connexins, and pannexins. There is ongoing characterization of the roles of each of these in cardiac metabolism. The totality of understanding is therefore still evolving.

Across mammalian species, the primary components of interendothelial junctions, are tight junctions and adherens junctions, promoting adhesion and restricting passage of substances circulating in the blood. These differ from the cardiac gap junctions that facilitate passage of solutes and small molecules between cells, discussed in the Distribution section. The endothelial connections of AJ and TJ require interaction with transmembrane proteins. These proteins bind to cytoskeletal and signaling proteins, ultimately connecting to actin filaments, linking junctional porosity to some degree with contractility (Dejana, 2004; Hsieh et al., 2006; Aird, 2007). 
Developmentally regulated protein isoforms and the maturational state of gap junction complexes determine myocardial contractility.

Various signaling pathways, described in detail elsewhere and beyond the scope of this review, also contribute to the regulation of endothelial junction permeability. Modulators to permeability include lipopolysaccharide, thrombin, and vascular endothelial growth factor. The endothelial junctions AJ and TJ are also involved in cell growth, apoptosis, and gene expression (Vandenbroucke et al., 2008; Yoon et al., 2014).

Passage across or into an endothelial cell includes a transcellular pathway (caveolae-mediated transcytosis or active transport) or the paracellular pathway of passive movement through the intercellular space between adjacent endothelial cells (e.g., lipophilic molecules traverse primarily by passive diffusion). The transcellular/caveolae pathway may require the involvement of receptors, pumps, or transport proteins, described as follows.

Connexins. In addition to endothelial cells, connexins (Cxs) are components of the blood vessel wall. Cxs, found in both gap junctions and the blood vessel wall, are membrane proteins found throughout the body. Six Cx subunits can form a connexon, or hemichannel, in the plasma membrane of the cell. This connexon can then appose to the connexin of an adjacent cell to form a gap junction channel. In blood vessels, the connexins allow for intercellular communication between endothelial cells, smooth muscle cells, and myoendothelial coupling. Within the heart overall, connexons are primarily recognized for permitting cell-to-cell, nonspecific passage of ions (Makowski et al., 1984; de Wit and Griffith, 2010). Transgenic mice have been used for elucidation of the role of connexins in arrhythmias and conduction disorders (Verheule and Kaese, 2013). Recent work examines the role of connexins in disturbances of the cardiac electrical conduction system (Santa Cruz et al., 2015).

Several different Cxs have been identified to date in human, mouse, rat, dog, and rabbit hearts (Coppen et al., 1999, 2001). A recent addition to this list is Cx26 (Moscato et al., 2018). Cx40, $\mathrm{Cx} 43, \mathrm{Cx} 44$, and $\mathrm{Cx} 45$ are the primary signature proteins of gap junctions, endocardium, coronary vessels, and aorta, but they have not been identified in myocardial capillaries. $\mathrm{Cx} 37$ has been detected in endothelial cells (Gros and Jongsma, 1996). Various studies have shown that the temporal and spatial expression of each protein, as well as abundance of each protein within the cardiac tissue, varies among species. Coppen et al. (1999) investigated the spatial expression pattern of $\mathrm{Cx} 40, \mathrm{Cx} 43$, and $\mathrm{Cx} 45$ in rabbits using dual-channel scanning confocal microscopy and determined that Cx40 and $\mathrm{Cx} 45$, but not $\mathrm{Cx} 43$, were expressed in the central SA node. Another investigation of immunolabeled $\mathrm{Cx} 40, \mathrm{Cx} 43$, and $\mathrm{Cx} 45$ in BALB/c mice, from embryonic day 12.5 to adult, determined that $\mathrm{Cx} 45$ is the earliest detectable connexin in the central conduction system and, in addition, is the only connexin expressed throughout the entire conduction system (Coppen et al., 2001). Another study found $\mathrm{Cx} 43$ to be the predominant $\mathrm{Cx}$ throughout the rat heart based on quantity, found on myocytes of both atria and ventricles (Van Kempen et al., 1996). This study also found that expression of $\mathrm{Cx} 43$ in the rat is uniform at birth and changes to punctate during the postnatal period. There is also some expression in fibroblasts and the electrical conduction system of humans (Purkinje fibers and intercalated discs), mice, and rats (Gourdie et al., 1993; Chen et al., 1994). Cx43 is also found in cardiomyocyte mitochondria of mouse, rat, pig, and human origin, possibly associated with cell death and survival (Boengler et al., 2005; MiroCasas et al., 2009; Jovic et al., 2012; reviewed in Rodríguez-Sinovas et al. (2012)). An association between connexin 43 and myosin VI, one of the sarcomeric motor proteins, has been demonstrated in mice to be necessary for gap-junction maintenance of morphology and intercellular communication (Waxse et al., 2017).

In the rat, $\mathrm{Cx} 40$ has been reported in the atria before birth and is highly expressed in the ventricle early in development, declining to minimal or no ventricular expression in adulthood (Van Kempen et al., 1996), similar to that seen in humans, in whom early studies showed $\mathrm{Cx} 40$ to be several-fold more abundant in fetal hearts compared with pediatric or adult hearts (Chen et al., 1994). Recent work using samples from humans has indicated that normal atrial conductance requires similar levels of expression of Cx40 and Cx43 (Gemel et al., 2014). Studies in patients with atrial fibrillation indicate decreased expression of $\mathrm{Cx} 40$ and the ion channel KCNA5 in atrial myocytes. This possible connection between structure and electrophysiology of atrial fibrillation has been extended into an examination of genetic variants of Cx40 and Cx37 (Zhang et al., 2017; Carballo et al., 2018). Cx40 is also expressed preferentially in the vascular endothelium of human coronary arteries and rat ventricular vascular endothelium (Bastide et al., 1993; Chen et al., 1994). Connexin 45 is reported to be widely but not highly expressed in the human, dog, rabbit, mouse, and rat heart, possibly helping to define the developing conduction system (Kanter et al., 1993; Coppen et al., 1998, 1999; Kim et al., 2016). In vitro work in a rat liver epithelial cell line suggests that expression of $\mathrm{Cx} 43$ with coexpression of inducible levels of $\mathrm{Cx} 45$ may modulate the size of the gap junction, a feature of importance across age groups (Grikscheit et al., 2008).

Recently, Cx26 mRNA and protein were found to be expressed in the rat, pig, and human cardiomyocytes. The protein was described in the cardiomyocytes of human atrium, rat atrium and ventricle, and the left ventricle of the pig. Unlike other cardiac connexins, these authors described the protein distribution as not at the intercalated disks but as distributed in the cytoplasm at the level of the mitochondria, myofibrils, and cytoplasmic vesicles (Moscato et al., 2018).

Various studies have shown that remodeling of connexin expression and gap junction organization occurs in adult heart conditions such as arrhythmia, ischemic heart disease, and sudden cardiac death (Severs et al., 2008; Molina et al., 2018; Visoná et al., 2018). Alterations can occur in the distribution, amount, and type of connexin expression during different types of heart disease in humans. Pharmacologic modulation of connexins has been proposed as a possible therapy for arrhythmias in patients with ischemic heart disease (De Vuyst et al., 2011). The therapeutic possibilities of cardiac connexins have been considered in a proposal for a modernization of the Vaughan-Williams classification of antiarrhythmic drugs. A new category of drugs acting on connexin-associated channels was suggested for several reasons, supported by investigations with agents that block or open the $\mathrm{Cx}$ channels, carbenoxalone and the peptide analog rotigaptide (ZP-123), respectively. The authors noted also the changes in gap junction that can accompany alterations in other action potential modifiers, such as remodeling, exemplified by fibrotic change. Changes in $\mathrm{Cx} 43$ expression were noted to occur in both dilated and hypertrophic cardiomyopathy (Lei et al., 2018).

Pannexins. Pannexins (PANXs) are a protein family with three members identified to date (PANX1, PANX2, Panx3) that have a different functional role from connexins. Based on their similar sequence homology with the invertebrate gap junctions and predicted topology similar to that of the gap junction proteins, it was originally suggested that they may form gap junction-like structures. To date, it has been shown that, unlike the connexin gap junction intercellular channels, pannexin oligomers form large-pore channels that are functional in single plasma membranes but not as intercellular channels in appositional membranes (Sosinsky et al., 2011). When open, they provide a conduction pathway between the cytosol and 
extracellular space. PANX1-triggered ATP release has been associated with pathologic fibrosis in canine cardiomyocytes, sympathetic activation in murine cardiac slices, atrial fibrillation in murine tissue, and possibly other processes (Sridharan et al., 2010; Johansen et al., 2011; Dong et al., 2016; Petric et al., 2016). The PANX channel has been shown to be inhibited by a peptide mimicking a sequence of trovafloxacin, potentially explaining the side effects of this antibiotic (Poon et al., 2014). The role of pannexins in physiologic and pathologic processes is not completely understood.

\section{Transporters}

Transporters are given a separate section in this review because of their function in both the absorption and excretion of drugs, xenobiotics, and multiple endogenous compounds (Table 1). The transporters are also involved in homeostatic functions and postnatal development of several organs, including the heart (Koepsell, 2013). Transporters are susceptible to many additional chemicals that can act as low- or high-affinity inhibitors (Koepsell et al., 2007). We briefly list the solute carrier transporters (SLCs) that have been identified in the heart.

The solute carrier family 22A (SLC22A) includes organic anion transporter (OAT) transmembrane proteins, organic cation transporters (OCT), and organic carnitine (zwitterion) transporters (OCTN); all these classes have been identified to varying extents in the heart.

OAT and OAT Polypeptides. The OAT polypeptides (OATPs) and OATs are widely distributed in tissues throughout the body, including the heart. The OATs and OATPs can transport a range of structurally unrelated compounds, including endogenous substances such as thyroid hormone, steroid conjugates, and xenobiotics. OATPs transport mainly large, hydrophobic organic anions, whereas OATs transport smaller and more hydrophilic anions. Despite the name, OATPs can transport both cationic and neutral compounds (Hagenbuch and Meier, 2003; Roth et al., 2012).

Expression of OATP4A1 mRNA is found throughout the human body, including in the adult human heart (Fujiwara et al., 2001). Compared with other OATPs, OATP4A1 has narrower substrate specificity, with estrone 3-sulfate, benzylpenicillin, and thyroid hormone reported as substrates (Tamai et al., 2000).

Messenger RNA for OATP2A1, originally identified as the prostaglandin transporter, is expressed in the adult human heart, as well as in numerous other tissues ( $\mathrm{Lu}$ et al., 1996). The activity of this transporter is needed for terminating prostaglandin signaling via prostanoid receptors. OATP2A1 can also function as an organic anion exchanger (Obaidat et al., 2012). SLCO2A1 has been identified in the pig heart (Van Poucke et al., 2009). Kamo et al. (2017) examined the effects of 636 Food and Drug Administration-approved drugs on OATP2A1 transport activity using human embryonic kidney cells (HEK293) cells expressing OATP2A1. The activity of OATP2A1 was strongly inhibited by 51 approved drugs and stimulated by 10 . Inhibitors included suramin, pranlukast, olmesartan, zafirlukast, and losartan, all with $\mathrm{IC}_{50}$ (inhibitor concentration where the response or binding is reduced by half) values less than $2 \mu \mathrm{M}$. Although it is difficult to speculate the specific clinical consequences of inhibiting or stimulating the activity of any of these receptors, it is not unreasonable to assume an effect of organ-specific impact.

OATP2B1 protein expression has been described in healthy human atria and ventricles and hearts with dilated and ischemic cardiomyopathy (Grube et al., 2006). Messenger RNA expression was found in all samples and localized to the vascular endothelium. Samples from those treated with atorvastatin exhibited decreased OATP2B1 compared with those that had not taken the medication. Other xenobiotics,

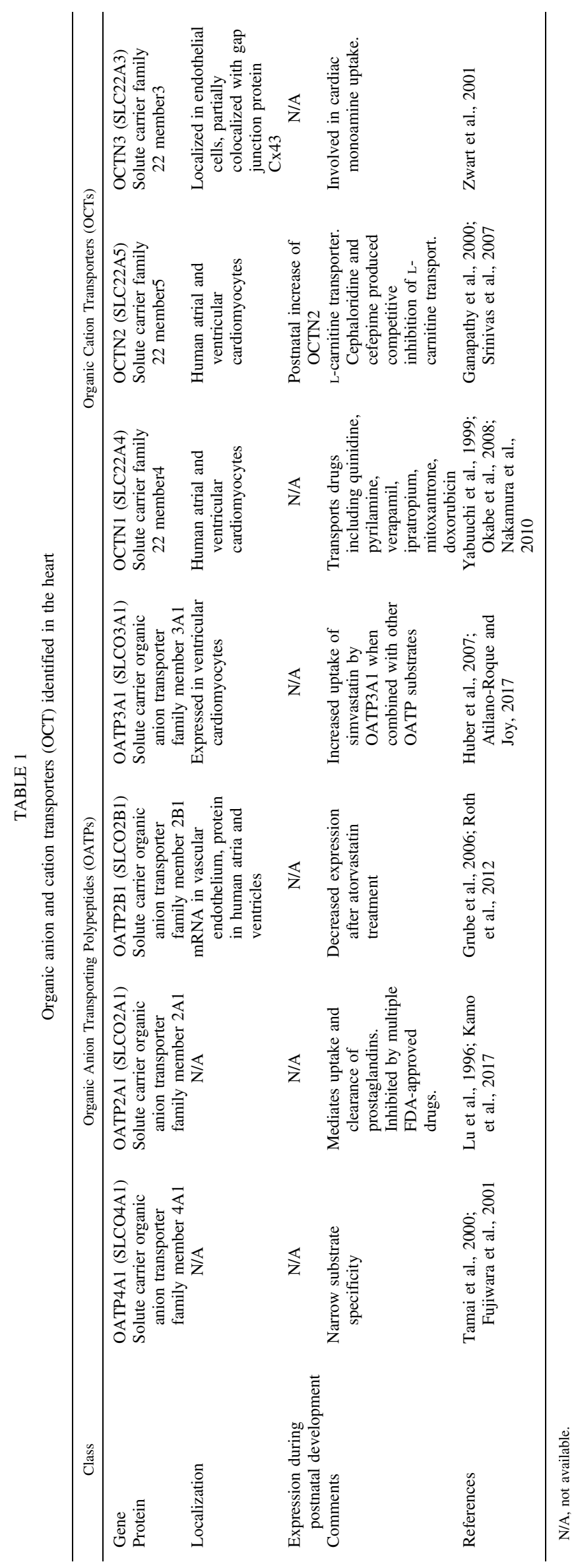


including aliskiren, bosentan, and pravastatin, have been demonstrated as substrates for OATP2B (Roth et al., 2012).

OATP3A1 is expressed in the human heart as well as in other organs, including testes, brain, lung, and spleen. Transported substrates include prostaglandin $\mathrm{E}_{1}$, thyroxine, and a nonspecified cyclic oligopeptide endothelin receptor antagonist (Huber et al., 2007). Adult human ventricular cardiomyocytes maintained in culture demonstrated that simvastatin modulated OATP3A1 expression in the cardiomyocytes and HEK293 cells transfected with the OATP3A1 gene. Simvastatin uptake was modulated by the $\mathrm{pH}$ of the cultures and the presence of other substrates of the OATP3A1 transporter, suggesting the potential for drug-drug interactions at the level of the heart (Atilano-Roque and Joy, 2017).

OCTs and Organic Carnitine Transporters. OCTs are involved in the cellular uptake of endogenous monoamines (e.g., epinephrine), neurotransmitters (e.g., acetylcholine, serotonin), metabolites (e.g., choline, creatinine), and a variety of drugs (e.g., metformin, cimetidine, famotidine, prazosin, verapamil). This SLC22 family includes organic carnitine transporters (OCTNs) (reviewed in Koepsell et al. (2007)).

OCTN1 (SLC22A4) expression at the DNA and protein levels has been identified in adult human atria and ventricular surgical samples and is localized to cardiomyocytes. A similar distribution is reported for mouse, rat, and rabbit (Wu et al., 2000; Lamhonwah and Tein, 2006; Iwata et al., 2008; McBride et al., 2009). Coexpression of this transporter in Chinese hamster ovary cells with the human ether-a-go-go-related gene channel potentiated a delayed rectifier $\mathrm{K}+$ channel receptor drug block (McBride et al., 2009). Other investigators have provided data supporting mitochondrial localization of OCTN1 using a variety of transfected human cell lines, as well as mouse hearts (Lamhonwah and Tein, 2006). Drugs that have been demonstrated to be transported by OCTN1 include quinidine, pyrilamine, verapamil, ipratropium, and the chemotherapeutic drugs mitoxantrone and doxorubicin (Yabuuchi et al., 1999; Okabe et al., 2008; Nakamura et al., 2010).

The OCTN2 (SLC22A5) has been identified in mouse (expressed on the plasma membrane), rat, pig, and human (Sekine et al., 1998; Tamai et al., 1998; Iwata et al., 2008; Luo et al., 2014). OCTN2 is expressed in several tissues, including the myocardium (human atria and ventricles), skeletal muscle, renal tubules, and intestine (Grube et al., 2006). Expression of this transporter is selectively decreased in human cardiomyopathy (Grube et al., 2011). OCTN2 is the primary highaffinity sodium-dependent L-carnitine transporter in humans (Srinivas et al., 2007). L-Carnitine is critically involved in the movement of long-chain fatty acids into the mitochondria for purposes of $\beta$-oxidation and removal of fatty acyl-coenzyme A metabolites from the mitochondria. The role of carnitine in postnatal development, and by implication the role of OCTN2, was examined in rat pups from postnatal day 4-20. The concentration of L-carnitine in both serum and cardiac tissue increased from postnatal day 4 to postnatal day 20 , with increases of $20 \%$ and $50 \%$ respectively. The expression of cardiac OCTN1 mRNA remained constant except for an increase at postnatal day 8 that was greater than all other time points. Expression of cardiac OCTN2 mRNA increased postnatally by $100 \%$, whereas OCTN3 mRNA was approximately $200 \%$ higher at postnatal day 8 than at postnatal day 4 and remained constant thereafter. These increases are also paralleled by increases in L-carnitine acyl transferases and carnitine palmitoyltransferase $1 \mathrm{~b}$ and $2 \mathrm{~b}$ mRNA expression (Ling et al., 2012). These results are consistent with the postnatal increase in fatty acid oxidation rates reported for the heart, attributed in part to maturation of mitochondrial systems and increased L-carnitine. Cell culture evaluation of human and rat OCTN2 transporters indicated that the antibiotics cephaloridine and cefepime produced $40 \%-90 \%$ competitive inhibition of carnitine transport, with rat OCTN2 showing somewhat less affinity for the antibiotics than the human transporter (Ganapathy et al., 2000).

Recent genetic analysis has linked a human biallelic variant in the SLC22A5 gene encoding the OCT2 with pediatric cardiomyopathy that is responsive to exogenously administered carnitine (Lahrouchi et al., 2017). Others have found variants of SLC22A17 and SLC22A7 to be predictive markers of anthracycline cardiotoxicity (Visscher et al., 2015).

OCT3 (SLC22A3) cDNA and/or protein has been identified in mouse, rat, and human tissues (Iversen, 1965; Verhaagh et al., 1999; Gründemann et al., 2002). This transporter is expressed in the heart as well as skeletal muscle, aorta, and human liver. This transporter is involved in monoamine uptake in the heart, demonstrated in OCT3null mice (Zwart et al., 2001). When examined in adult human failing and nonfailing hearts, immunostaining showed that OCT3 expression in the left ventricles was localized with endothelial cells and partially colocalized with gap junction protein connexin-43. No difference in OCT3 expression was found between failing and nonfailing hearts (Solbach et al., 2011).

Madin-Darby canine kidney II cells overexpressing the cardiac transporters OCT1, OCT3, OCTN1, and OCTN2 were used to examine the interaction of these transporters with cardiovascular drugs. OCT1 and OCTN1 were each inhibited to $50 \%$ or less residual transport activity by 11 of the 21 tested drugs. OCT3 residual transport activity was reduced to $30 \%$ or less by nifedipine, propranolol, and verapamil. OCTN2 was essentially unaffected, with transport activity remaining $70 \%$ or greater. Drugs tested were amiodarone, atenolol, atorvastatin, atropine, bisoprolol, carvedilol, digoxin, diltiazem, flecainide, ipratropium bromide, lidocaine, metoprolol, molsidomine, nadolol, nifedipine, propafenone, propranolol, sotalol, spironolactone, talinolol, and verapamil (Grube et al., 2011).

\section{Distribution}

Distribution may be seen from several different perspectives, such as distribution of a chemical to the heart from the general circulation (distribution to the heart), as well as movement throughout the heart once the endothelial barrier has been crossed (distribution through the heart). Cardiomyocytes communicate and are physically linked by the intercalated disk (ID), a structure unique to the heart. The gap junction component of the ID is involved in the rapid electrical transmission between cells, as well as passage of small molecules. Relatively recently, the interactions of components of the ID have been redescribed as transitional junctions, perinexus, and area compositae (also called composite junctions or connexomes). Myriad affiliated proteins have also been identified (Forbes and Sperelakis, 1985; Vermij et al., 2017). The overall function of the ID is that of communication, providing passage of ions as well as signaling molecules. Little easily accessible information is available about its potential involvement in xenobiotic distribution throughout the heart.

The gap junction provides direct communication between cardiac cells primarily for electrical communication by allowing ions to pass between cells, and thus it helps coordinate depolarization. The passage of ions occurs within the pore of a gap junction that is formed by an assembly of connexin molecules.

The transitional junction is a recently recognized subcellular functional domain of the ID (Bennett et al., 2006). Its location in the ID is where the myofibrils lead into the adherens junction. It is hypothesized that this domain may allow for direct communication between the ID and contractile apparatus by acting as an anchor point for titin, the largest known protein, described as the third filament system for the sarcomere 
TABLE 2

ATP-binding cassette and facilitative glucose transporters identified in the heart

\begin{tabular}{|c|c|c|c|c|}
\hline \multirow[t]{2}{*}{ Class } & \multicolumn{2}{|c|}{ ATP-Binding Cassette (ABC) } & \multicolumn{2}{|c|}{ Facilitative Glucose } \\
\hline & $A B C B 1$ & $A B C C 5$ & $S L C 2 A 1$ & $S L C 2 A 4$ \\
\hline Protein & $\begin{array}{l}\text { P-glycoprotein }(\mathrm{P}-\mathrm{gp}) \text { or multidrug } \\
\text { resistance protein } 1(\mathrm{MDR} 1)\end{array}$ & MRP5 & GLUT1 & GLUT4 \\
\hline Localization & N/A & N/A & & \\
\hline $\begin{array}{l}\text { Expression during } \\
\text { postnatal development }\end{array}$ & $\begin{array}{l}\text { Endothelial cells of cardiac } \\
\text { arterioles and capillaries. }\end{array}$ & $\begin{array}{l}\text { Vascular smooth muscle cells, } \\
\text { cardiomyoccytes, vascular } \\
\text { endothelial cells. }\end{array}$ & N/A & N/A \\
\hline Comments & $\begin{array}{l}\text { Drug efflux pump. Broad specificity } \\
\text { includes digoxin, beta adrenergic } \\
\text { agonists. Individual variability of } \\
\text { expression contributes to } \\
\text { variability of response. }\end{array}$ & $\begin{array}{l}\text { Transports cyclic nucleotides and } \\
\text { some nucleoside monophosphate } \\
\text { analogs. Higher expression levels } \\
\text { found in ischemic } \\
\text { cardiomyopathy. }\end{array}$ & & $\begin{array}{l}70 \% \text { of the glucose transporters } \\
\text { expressed in adult human } \\
\text { heart.are insulin-regulated } \\
\text { but also influenced by fatty } \\
\text { acids and thyroid hormone. }\end{array}$ \\
\hline References & $\begin{array}{l}\text { Karlsson et al., 1993; Westphal } \\
\text { et al., 2000; Meissner et al., } 2004\end{array}$ & Dazert et al., 2003 & $\begin{array}{l}\text { Wang and } \mathrm{Hu}, 1991 ; \\
\text { Santalucía et al., } 1992\end{array}$ & $\begin{array}{l}\text { Wang and Hu, 1991; Santalucía } \\
\text { et al., } 1992\end{array}$ \\
\hline
\end{tabular}

GLUT, facilitative glucose transporter; N/A, not available.

and important in the process of myofibrillogenesis (Bennett et al., 2006; Myhre and Pilgrim, 2014). It has also been proposed that the transitional junction is the site where new sarcomeres are added to the myofibril, providing elongation or growth of the cardiomyocyte during increased cardiac load (Vermij et al., 2017).

The perinexus, another functional region of the intercalated disk, is the area around the plaque of functional gap junctions in which free connexons (connexin hemichannel) interact with zonula occludens-1 (ZO-1). The ZO-1 regulates size, number, and localization of the gap junctions, thus suggesting a potential regulatory role in their distribution. Named for its proximity to bordering gap junctions, the perinexus has been described as a microdomain, enriched in connexons, and containing sodium channels $\mathrm{Na}_{\mathrm{v}} 1.5, \mathrm{Na}_{\mathrm{v}} 1.3$, several potassium channels (including $\mathrm{K}_{\mathrm{v}}$ and $\mathrm{K}_{\mathrm{ir}}$ ), connexin 43, and other protein-protein interactions, suggesting facilitation of distribution to several ion channels. Another role may be in the contribution to electrical coupling between cardiomyocytes and, thus, cardiac conduction (Rhett et al., 2011, 2013; Rhett and Gourdie, 2012).

The adherens junctions (AJ, sometimes called fascia adherens) occur at cell-cell junctions and help to transduce and transmit contractile forces by anchoring myofibrils and connecting actin filaments from adjacent cells (Vermij et al., 2017). As reviewed by Henderson et al. (2017), AJs have a transmembrane component composed of cadherin proteins and a cytoplasmic plaque component comprising catenin proteins. The $\mathrm{N}$-cadherin protein homodimerizes with $\mathrm{N}$-cadherins from adjacent cells, creating points of calcium-dependent intercellular connection.

During development, gap junctions appear at the ID after formation of the adherens junctions. Vreeker et al. (2014) examined the time frame of human postnatal assembly of the adherens junction proteins $\mathrm{N}$-cadherin and ZO-1 and the desmosomal proteins plakoglobin, desmoplakin, and plakophilin-2. They found that these proteins were initially diffuse and located laterally and then were localized to the ID at approximately 1 year after birth. They also reported the detection of the $\mathrm{Na}_{\mathrm{v}} 1.5$ channel in the ID at 2 years after birth and the connexin 43 protein at 7 years after birth in humans, consistent with the findings of other investigators.

The area composita or adhesion junction is a term proposed by Borrmann et al.(1999) and Franke et al. (2006). An intriguing feature of the area composita and the ID region overall is the relatively prolonged period of postnatal maturation consistently found in rats, dogs, and humans (Pieperhoff and Franke, 2007). In rats, gap junctions, as determined by the location of connexin 43 , and adherens junctions, as determined by the locations of desmoplakin and $\mathrm{N}$-cadherin, went from a dispersed distribution across myocyte cell membranes at birth to a polarized distribution at the cell termini, that is, the developing intercalated disks, by postnatal day 20. From postnatal day 20 to postnatal day 90 , the gap junctions became progressively concentrated in these zones. Similar findings have been reported for 1- and 3-month-old dogs. The progression of the process in 3-month-old dogs was similar to that in a 20-day old rat (Angst et al., 1997).

A study of material obtained from pediatric surgical patients aged from 4 weeks to 15 years showed the neonatal human to have a multifocal distribution of connexin 43 gap junctions over the entire surface of the ventricular myocytes. With increasing age, the distribution of the gap junctions became localized to the IDs, reaching an adult pattern by approximately 6 years of age (Peters et al., 1994). The similarity of results in humans, rats, and dogs suggests that this change in the distribution and organization of gap junctions and cellular adhesion is an important process in cardiac maturation (Angst et al., 1997). Within the muscle fibers of the heart, most desmosomes and adherens junctions integrate into composite junctions; however, in the conduction fibers, there is less integration of these two components. A study of Purkinje fibers indicated the presence of discrete desmosomes, discrete adherens junctions, and composite junctions similar to those of the ID (Pieperhoff et al., 2010).

Once a drug moves through the blood-vessel wall, it may traverse the cardiomyocytes and the extracellular matrix, depending on the properties of the xenobiotic and intrinsic properties of the developing animal, which may include the proportion of extracellular water to body fat and the maturity of transport mechanisms. In general, a newborn infant has a higher proportion of water as body weight (70\%-75\%) compared with an adult (50\%-55\%), approximately 5\% less fat tissue, and $25 \%$ less muscle tissue. These relative differences in body composition will affect the volume of distribution of drugs that are distributed within these tissues (Koren, 1997).

Distribution of drugs to the heart will be, in part, due to the movement of the blood, contact with the endothelium, residence time (or plasma half-life), and the chemical properties of the material. Distribution of a drug is characterized by the ratio of total concentration of compound in the tissue to total concentration of compound in the plasma at steady state $\left(K_{\mathrm{p}}\right)$. In a recent review article of the drug distribution based on human samples from cardiac surgeries and forensic medical studies, $K_{\mathrm{p}}$ values for different types of drug were summarized (Tylutki and Polak, 2015). In general, the ratios of drug concentration in pericardial fluid and cardiac tissue to the plasma concentration for antibiotics were below 0.5 . For amiodarone, an antiarrhythmic compound, the ratio had a mean value of 23 , with the highest concentration demonstrated in cardiac fat, 
possibly creating a slow-release depot. On average, the myocardial concentration was 10 times greater than that in the plasma. Similarly, concentrations of digoxin were higher in the myocardium than in the plasma.

Physicochemical attributes of the drug itself must be considered for the distribution phase. Lipophilic drugs and organic bases (e.g., tricyclic antidepressants, digoxin, cocaine) tend to accumulate in the myocardium with high affinity. Intraindividual variation in tissue concentrations from one region of the heart to another has been reported. As this is a developing area, there is reasonable speculation that multiple mechanisms are involved in the distribution of drugs throughout the heart (Tylutki and Polak, 2015).

\section{Metabolism}

Phase 1. Phase 1 metabolism is generally viewed as adding or unmasking a functional group, by oxidation, reduction, or hydrolysis. The main actors in these transformations are the cytochrome P450 (P450) families and the cytosolic aldehyde oxidases.

P450. P450 enzymes are recognized as critical agents of xenobiotic metabolism, important for the metabolism of foreign and endogenous compounds. Several P450 isozymes have been identified in the human heart (Table 3), To date, most cardiac P450 exploration has been in adult hearts. Little information was found in the literature for a developmental timeline, or ontogeny, for the cardiac P450s.

CYP2J2 is a predominant heart isoform that has been determined to be constitutively expressed in the adult human heart, with marked interindividual variation (Wu et al., 1997). Its primary function in the heart is drug metabolism, biosynthesis of epoxyeicosatrienoic acid (EET), and nitrous oxide production by metabolism of NCX-4016, a nitric oxide-releasing aspirin. EETs are endogenous molecules from the metabolism of arachidonic acid (AA), which is important in the regulation of cardiovascular homeostasis. An examination of the mRNA and protein levels in the adult human heart, aorta, and coronary arteries showed that CYP2J2 mRNA is highly variable but present in much greater abundance than either CYP2C8 or CYP2C9. Also, in nondiseased adult human hearts, CYP2J2 protein was identified in cardiomyocytes and endothelium of the cardiac vessels. A number of functional polymorphisms of CYP2J2 have been identified in humans, some of which may be associated with coronary artery disease, where overexpression may be one of several factors that contribute to protection (King et al., 2002; Spiecker et al., 2004; Lee et al., 2005; Aliwarga et al., 2018). Whereas cardiac CYP2J2 is relatively minor compared with hepatic metabolism, CYP2J2 has a significant role in some drugs. One example is doxorubicin. Transgenic mice overexpressing cardiomyocyte-specific human CYP2J2 were administered doxorubicin either for 3 days or chronically for 5 weeks. After the acute treatment, hearts of the transgenic overexpressers showed less doxorubicin-induced cardiomyocyte apoptosis compared with wild-type hearts. After chronic treatment, cardiac function, as assessed by echocardiography, was significantly higher in the transgenic CYP2J2 overexpressers than in wild-type mice. Comparison of the microsomes from the WT and transgenic mice showed faster doxorubicin turnover in the CYP2J2 mice. A selective epoxygenase inhibitor, MS-PPOH, blocked the enhanced metabolism observed in the transgenic mice (Zhang et al., 2009). Little is known about the developmental expression of CYP2J2. One study examined human fetal tissue for expression of CYP2J 2 mRNA and found it to be expressed ubiquitously in human fetal liver, heart ( $n=5$ samples), kidney, lung, intestine, and brain (Gaedigk et al., 2006).

CYP2C9 cardiac isoform is inducible and involved with drug metabolism, biosysnthesis of EET, and reactive oxygen species

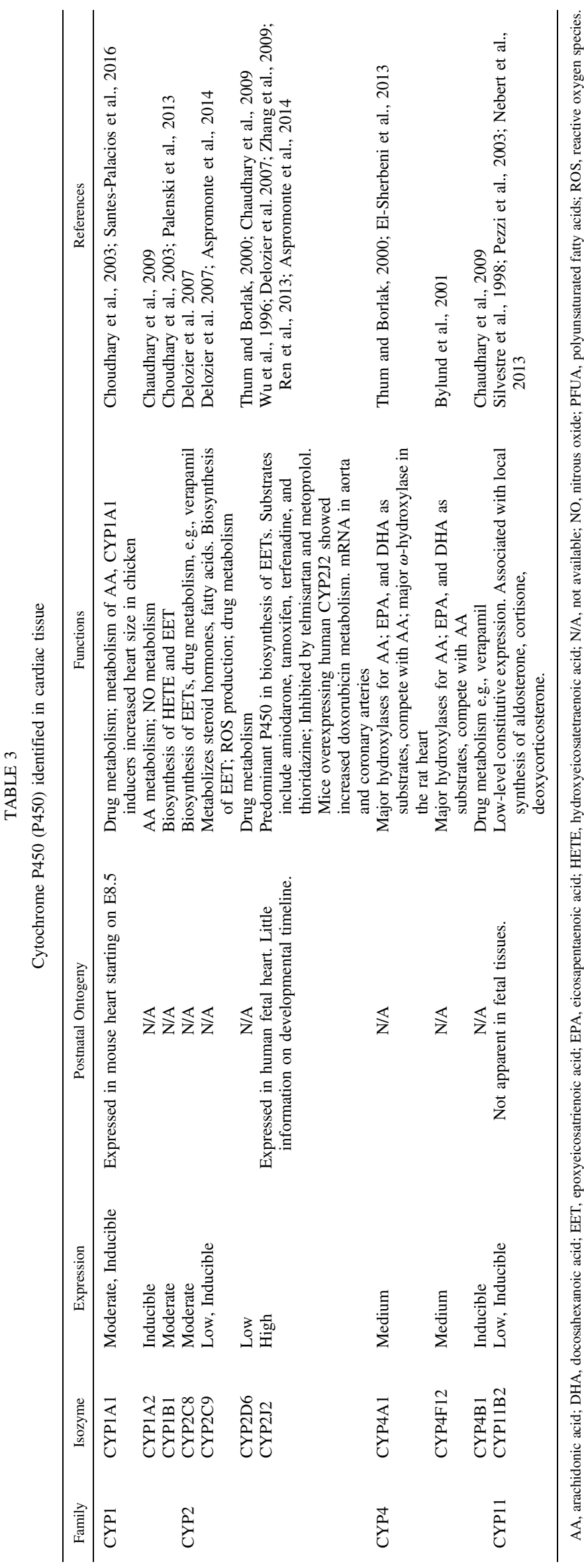

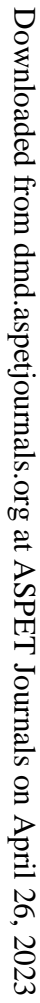


production. CYP2C9 protein was identified in endothelial cells of the aorta and coronary arteries of nondiseased human hearts (Delozier et al., 2007; Askari et al., 2013). In one ischemic heart, CYP2C9 mRNA was more abundant than either CYP2J2 or CYP2C8. As in many other studies of cardiac metabolism, this study had a relatively small number of samples $(n=8)$, all of which were from adult (aged $>30$ years) hearts (Delozier et al., 2007).

CYP11B2, aldosterone synthase, is constitutively expressed in the heart at low levels and is associated with local synthesis of aldosterone, corticosterone, and deoxycorticosterone (Silvestre et al., 1998). The mRNA for CYP11B2 has been identified in myocardium of strokeprone, spontaneously hypertensive rats at levels significantly greater than those of age-matched Wistar-Kyoto rats (Takeda et al., 2000) Endomyocardial biopsy samples from patients with acute myocarditis and stable heart transplant recipients with no evidence of rejection (negative controls) were examined for evidence of CYP11B2 expression. Of 16 samples from myocarditis patients, 13 showed cytoplasmic staining of the cardiomyocytes, compared with 2 of 16 transplant patients, indicating local expression of aldosterone synthase protein (Cardona et al., 2019).

Enzymes CYP2C8, CYP2C9, and CYP2J2 are the primary sources generating EET. Whereas the CYP2C and CYP2J enzymes are the major epoxygenases, CYP4A and CYP4F subfamilies function as hydroxylases, both of which subfamilies have been identified in human and canine hearts (Nithipatikom et al., 2004; Zordoky and El-Kadi, 2008). As hydroxylases, the CYP 4A/4F isoforms are involved in 20hydroxyeicosatrienoic acid (HETE) synthesis by AA metabolism. Hydroxylases can convert AA to 16-, 17-, 18-, 19-, 20-HETE, but CYP4A/F converts AA only to 20-HETE. As reviewed by Jamieson et al. (2017), eicosapentaenoic acid and docosahexaenoic acid may compete with arachidonic acid (AA) as substrates for these enzymes. Mono-oxygenation of eicosapentaenoic acid and docosahexaenoic acid leads to the production of putative active metabolites, known as resolvins and protectins, that are involved in the resolution of inflammation. The EETs and HETEs tend to have opposite biologic effects. The EETs generally produce vasodilation and angiogenesis, whereas the HETEs in general are associated with vasoconstriction and hypertension (Oni-Orisan et al., 2016). Some in vitro work suggests that individual HETEs have unique properties. The effect of enantiomers of 19-HETE on the AA metabolites produced by cultured rat cardiomyoblast (H9c2) cells and human cardiomyocytes (RL-14) was compared. In rat and human cardiomyocytes, both the 19(R)-HETE and the 19(S)-HETE decreased the levels of several of the midchain HETEs. Neither enantiomer of 19-HETE produced significant effects on mRNA or protein for CYP2B6, CYP2C8, or CYP2J2. The S-enantiomer increased CYP4F2 and CYP4F11 mRNA and protein expression levels (Shoieb and El-Kadi, 2018). The opposite roles of the EETs and HETEs suggest that the ratios between the two classes are important. Further, it appears that the proportions of EETs and HETEs within each class may also be important in cardiovascular health or development of pathologies.

Once produced by CYP2C or CYP2J, EETs are rapidly hydrolyzed to dihydroxyeicosatrienoic acids by soluble epoxide hydrolase (Jamieson et al., 2017). Several marketed therapeutic agents have been demonstrated to be CYP2J2 substrates, including amiodarone, tamoxifen, terfenadine, and thioridazine (Lafite et al., 2006; Lee et al., 2010). Telmisartan and metoprolol are both capable of selectively inhibiting CYP2J2 (Ren et al., 2013). Whether these xenobiotics affect EET production is not clear due to the complexity of overall regulation (Deng et al., 2010).

Another class of substrates for CYP2J2 is $\omega-3$ and $\omega-6$ endocannabinoids, endogenously produced from polyunsaturated fatty acids. The metabolism of endocannabinoids produces endocannabinoid epoxides, reported to be vasodilatory and anti-inflammatory (McDougle et al. 2017). Phytocannabinoids have recently also been shown to be substrates of CYP2J2. The different classes of phytocannabinoids are both competitive and noncompetitive inhibition of the endogenous molecule anandamide (Arnold et al., 2018).

Rabbits, nonhuman primates, and dogs are similar to humans in having CYP2J member identified within the heart. Polymorphisms of the CYP2J member(s) have been proposed to lead to altered organ function. In the case of polymorphisms associated with cardiovascular disease, the results between studies have not been consistent (Aliwarga et al., 2018). Rats and mice have multiple CYP2J enzymes and pseudogenes. Not all rat enzymes possess epoxygenase activity (Askari et al., 2013). Characterization of the postnatal functional activity of this group of metabolizing enzymes in the heart of any species was minimal to nonexistent. Recent publications by Aliwarga et al. (2018) and Solanki et al. (2018) provide detailed discussions of the role of CYP2J2 in cardiovascular biology.

Dog hearts express several CYP4A and CYP4F enzymes. CYP4A37, CYP4A38, and CYP4A39 are present in beagle hearts at relatively low expression levels. The amino acid sequences for these three enzymes share $\geq 90 \%$ identity to one another and are approximately $71 \%$ and $78 \%$ identical to rat CYP4A1 and human CYP4A11, respectively (Graham et al., 2006). Studies by El-Sherbeni et al. (2013) indicate that CYP4A1, although expressed at a relatively low level, is the major $\omega$-hydroxylase in the rat heart. The HETEs have numerous actions in the heart, including vasoconstriction and interaction with various cardiac ion channels (Aspromonte et al., 2014).

Identification of P450 enzymes within the heart suggests the possibility of tissue-specific metabolism, either beneficial or adverse. Modulating the activity of the cardiac P450s, that is, induction or inhibition, is also possible. While the inhibition or induction of CYPs in liver or lungs has received extensive investigation, this area of work for the heart is developing. Mice overexpressing human cardiomyocyte CYP2J2 showed increased metabolism of doxorubicin in conjunction with decreased toxicity (Zhang et al., 2009). Cocaine is another drug that has been demonstrated to induce CYP2J2 mRNA (Wang et al., 2002). Studies by Zordoky et al. (2008) demonstrated isoproterenol induction of CYP1A1, CYP1B1, CYP4A3 and inhibition of CYP2C11 and CYP2E1 in hypertrophied rat hearts.

Aldehyde Oxidase. Mammalian aldehyde oxidase (AOX) comprises a group of soluble phase 1 enzymes located in the cytosolic fraction of the cell. AOX has marked interspecies variability of expression that has been associated with profound differences in pharmacokinetics between nonclinical and clinical studies, leading to failure of drug development (Jensen et al., 2017). The highest mRNA for AOX isoforms in human tissues is located in the adrenal gland and liver. Essentially no AOX mRNA was identified in the heart of either healthy mice or humans (Terao et al., 2016). Ghaffari et al. (2012) demonstrated AOX activity in heart tissue from control and rats with diabetes mellitus. The enzymatic activity was localized to the organ but not to a cell type or structure. This is a rapidly expanding area of interest and further species-specific information is likely to be forthcoming.

Phase 2. Several enzyme classes constitute the predominant agents of what is referred to as phase 2 metabolism. This has been historically viewed as a hydrophilic enhancement of a CYP-modified molecule; however, some of the phase 2 enzyme classes may conjugate molecules that already have groups, such as hydroxyls, carboxyls, or suitable amines. The major transforming enyzmes are transferases: UDP-glucuronosyltransferases (UGT), sulfotransferases (SULTs), $\mathrm{N}$-acetyl transferases (NAT), and glutathione S-transferases (GSTs). 
TABLE 4

Metabolic components identified in human heart

\begin{tabular}{|c|c|c|}
\hline & Component & Reference(s) \\
\hline Connexins & $\mathrm{Cx} 26, \mathrm{Cx} 43, \mathrm{CX} 40, \mathrm{Cx} 45$ & Chen et al., 1994; Boengler et al., 2005; Miro-Casas et al., 2009; Moscato et al., 2018 \\
\hline OATP & mRNA for $4 \mathrm{~A} 1,2 \mathrm{~A} 1$ protein for $2 \mathrm{~B} 1,3 \mathrm{~A} 1$ & $\begin{array}{l}\text { Lu et al., 1996; Fujiwara et al., 2001; Grube et al., 2006; Huber et al., 2006; } \\
\text { Roth et al., } 2012\end{array}$ \\
\hline OCTN & Protein for OCTN1, OCTN2 & McBride et al., 2009 \\
\hline OCT & Protein for OCT3 & Verhaagh et al., 1999 \\
\hline Area composita and ID & Prolonged development after birth & Pieperhoff and Franke, 2007 \\
\hline Sulfotransferases & mRNA SULT1C4, SULT 2B1 & Sakakibara et al., 1998; Runge-Morris, 2013 \\
\hline P450 & mRNA and protein $2 \mathrm{C} 8,2 \mathrm{C} 9,2 \mathrm{~J} 2,11 \mathrm{~B} 2,4 \mathrm{~A}, 4 \mathrm{~F}$ & $\begin{array}{l}\text { King et al., 2002; SPiecker et al., 2004; Lee et al., 2005; Aspromonte et al., 2014; } \\
\text { Aliwarga et al., } 2018\end{array}$ \\
\hline $\mathrm{ABC}$ transporters & mRNA and protein P-glycoprotein, MRP5, ABCC9 & Meissner et al., 2002, 2004; Dazert et al., 2003 \\
\hline Glucose-related & Protein GLUT1, 3, 4, 8, 10, 11, 12 and SGLT1 & $\begin{array}{l}\text { Kayano et al., 1988; Kraegen et al., 1993; Brosius et al., 1997b; Grover-McKay } \\
\text { et al., 1999; Di Franco et al., } 2017\end{array}$ \\
\hline
\end{tabular}

ABC, ATP-binding cassette; GLUT, facilitative glucose transporter; ID, intercalcated disk; MRP, multidrug resistance proteini; OATP, organic anion transporting polypeptide; OCT, organic cation transporter; OCTN, organic carnitine transporter; P450, cytochrome P450; SULT, sulfotransferase.

Other transferases also exist, and cumulatively constitute a fair proportion of metabolic events (Jancova et al., 2010).

Uridine 5'-Diphosphoglucuronosylransferase (UDPGlucuronosyltransferases, or UGT). The primary enzymes for glucuronidation, UGTs are membrane bound in the endoplasmic reticulum and are similar to sulfotransferases. UGTs are important in the metabolism of both xenobiotics and endogenous compounds such as bilirubin and steroid hormones. To date, more than 22 functional human UGT proteins have been identified, some with broad tissue distribution and others that are tissue specific. In addition to the liver and gastrointestinal tract, the kidney, brain, and nasal epithelium have been demonstrated to have UGT capacity, but there is little evidence of cardiac glucuronidation activity (Lazard et al., 1990; Sutherland et al., 1993; King et al., 1999; Chen et al., 2005). A study using adult $(n=3)$ human tissues examined UGT mRNA in various tissues, including the heart. Using reverse transcriptionpolymerase chain reaction, only trace amounts of mRNA for UGTA1, UGT2A, and 2B families were identified in the heart, with no cellular type or location identified (Court et al., 2012). An examination of five different strains of mice showed Ugt1a2 and Ugt2b5 protein to be specific to the hearts of male mice (Chen et al., 2017).

The role of thyroid hormones in postnatal cardiac development has been demonstrated (reviewed in Li et al. (2014)). It has also been shown that UGTs glucuronidate both xenobiotics and endogenous substances, including the thyroid hormone thyroxine (Yamanaka et al., 2007). It is speculative at this moment as to whether there is some form of local, organ-specific regulation of the thyroid involvement in postnatal cardiac development, an area that may be important in developmental toxicity or localized therapeutic effects.
Sulfotransferases. Cytosolic SULTs are involved in the sulfonation of xenobiotics and endobiotics such as steroids, bile acids, and thyroid hormones, playing an important role in endocrinology. The membrane-bound SULTS are associated with the Golgi apparatus of the cell. Substrates for these isoforms include lipids, peptides, and proteins, with sulfonation of the endogenous material causing structural and functional change (Li et al., 2014). The SULT enzymes are unique in significant expression early in life, in contrast to UDPGST. Sulfotransferase activity has been demonstrated in fetal hepatic cytosol preparations, suggesting a role in early metabolism. Investigations by Alnouti and Klaassen (2006) showed mRNA for Sult1a1, Sult1c1, and Sult1e1 (trace amounts) in the hearts of 8-week- old mice of both sexes. The mRNA for Sult3a1 and Sult5a1 were identified in male mouse hearts only, a phenomenon later characterized as androgen-dependent (Alnouti and Klaassen, 2006, 2011). RNA for SULT1C4 was found in the fetal human heart (Sakakibara et al., 1998) Sult1c1 mRNA expression after birth in humans has not been detected in cardiac tissues to any significant amount, and only trace amounts of mRNA have been detected for Sult2b1. There appears to be somewhat greater expression of SULTs in the hearts of male rats. Sex-related expression and distribution of SULT mRNA have been described for Sprague-Dawley rats. Messenger RNA for SULT1A1, as well as trace amounts of SULT1E2, was identified in the hearts of male rats. No mRNA for SULTs was identified in female rat hearts (Dunn and Klaassen, 1998). Pigs lack or show poor sulfonation compared with other species. Minimal evaluation of porcine cardiac phase 2 metabolism is described in the published literature (Helke and Swindle, 2013).

Mueller et al. (2015) raise an interesting consideration in the active transmembrane transport needed for cellular influx of hydrophilic

TABLE 5

Metabolic components identified in rat heart

\begin{tabular}{|c|c|c|}
\hline & Component & Reference(s) \\
\hline Connexins & $\mathrm{Cx} 26, \mathrm{Cx} 43, \mathrm{CX} 40, \mathrm{Cx} 45$ & Van Kempen et al., 1996; Moscato et al., 2018 \\
\hline OCTN & mRNA, protein for OCTN1, OCTN2 & Wu et al., 2000 \\
\hline OCT & Protein for OCT3 & Verhaagh et al., 1999; Gründemann et al., 2002 \\
\hline Area composita and ID & Prolonged development after birth & Pieperhoff and Franke, 2007 \\
\hline Sulfotransferases & mRNA SULT1A1, SULT1E2, male rats only & Dunn and Klaassen, 1998 \\
\hline P450 & mRNA 2J2, 2C11, 2E1, 4F, 11B2, 2B6, 2C8, 4A1 & $\begin{array}{l}\text { Takeda et al., 2000; Askari et al., 2013; El-Sherbeni et al., 2013; Shoieb } \\
\text { and El-Kadi, } 2018\end{array}$ \\
\hline Glucose-related & Protein GLUT1, 4 & Wang and Hu, 1991; Santalucía et al., 1992 \\
\hline NAT & cDNA for NAT1 and NAT2 mRNA NAT1, NAT2, NAT3 & Walraven et al., 2007; Barker et al., 2008 \\
\hline
\end{tabular}

GLUT, facilitative glucose transporter; ID, intercalcated disk; NAT, N-acetyltransferase; OCT, organic cation transporter; OCTN, organic carnitine transporter; P450, cytochrome P450; SULT, sulfotransferase. 
TABLE 6

Metabolic components identified in mouse heart

\begin{tabular}{|c|c|c|}
\hline & Component & Reference(s) \\
\hline Connexins & $\mathrm{Cx} 43, \mathrm{CX} 40, \mathrm{Cx} 45$ & Coppen et al., 2001 \\
\hline OCTN & Protein for OCTN1, OCTN2 & Iwata et al., 2008; \\
\hline OCT & cDNA for OCT3 & Verhaagh et al., 1999 \\
\hline Sulfotransferases & $\begin{array}{l}\text { mRNA Sult 1a1, Sult1c1, Sult1e1 mRNA Sult3a1, Sult5a1 in } \\
\text { males only }\end{array}$ & Alnouti and Klaassen, 2006, 2011 \\
\hline $\mathrm{P} 450$ & mRNA $2 \mathrm{~J} 2,4 \mathrm{~A}$ & \\
\hline Glucose-related & Protein GLUT1, SGLT1, GLUT3, GLUT8, GLUT10, GLUT12 & $\begin{array}{l}\text { Banerjee et al., 2009; Aerni-Flessner et al., 2012; } \\
\quad \text { Maria et al., } 2018\end{array}$ \\
\hline UDP-glucuronosyl transferases & mRNA Ugt1a2, Ugt2b5, male mice only & Chen et al., 2017 \\
\hline ABC transporters & $\mathrm{ABCC} 9$ & Fahrenbach et al., 2014 \\
\hline
\end{tabular}

ABC, ATP-binding cassette; GLUT, facilitative glucose transporter; OCT, organic cation transporter; OCTN, organic carnitine transporter; P450, cytochrome P450; SULT, sulfotransferase.

sulfated steroids. The SLCO and SLC22A superfamilies of SLC transporters have members associated with sulfated steroid transport. To date, there is a paucity of information concerning the relationship or lack thereof of the SULTs and SLC22A in the heart. The multidrug resistance protein (MRP) has been associated with cellular efflux of sulfated steroids and has also been identified in the heart. As proposed by Meuller et al. (2015), the relative tissue expression of OATP and MRP relates to total intracellular concentrations of steroids, suggesting a partnering effect of metabolic and transport systems. Overall regulation in general and coordinate regulation in particular are incompletely understood at this time.

$\mathbf{N}$-Acetyltransferases. The $\mathrm{N}$-acetyltransferases (NATs) are cytosolic enzymes with at least two functional forms, NAT1 and NAT2, found in humans. A recent study examined the tissue expression patterns of NAT1 and NAT2 in cynomolgus monkeys. Very low levels of mRNA for both were detected in the heart, with greatest expression located in the liver, followed by the kidney. The investigators point out that human variability of NAT activity, sometimes described in terms of fast or slow acetylators for drugs such as isoniazid or sulfamethazine, can be attributed in large part to genetic variants. The interanimal variability in NAT activity in nonhuman primates may similarly be due to genetic variants, information of potentially great importance and are not necessarily available (Uno et al., 2018). Species variability is a critical consideration for this family of enzymes. For example, NATs are lacking in the dog but occurring at high levels in swine (described in the liver) and rodents (Trepanier et al., 1997; Collins, 2001; Helke and Swindle, 2013). In addition to rat NAT1 and NAT2, a third rat enzyme, rNat3*1 was identified. Evaluating tissue from F344 rats, cDNA for rNAT1 was found in the heart, followed by lower levels of expression of cDNA for rNAT2 and no detectable rNAT3 (Walraven et al., 2007). Further work demonstrated mRNA concentration for all three rNATS in the hearts of F344 rats. The levels of mRNA for rNAT3 were consistently lower than for the rNAT1 and rNAT2, suggesting lower constitutive expression but leaving open questions about tissue specific expression or linkage to a specific developmental stage or disease state (Barker et al., 2008).

\section{Excretion}

ATP Binding Cassette Superfamily of Transport Proteins. ATPbinding cassette $(\mathrm{ABC})$ transporters, which use energy from ATP hydrolysis to move substances against chemical or electrical gradients, is one of the largest transporter superfamilies (Table 2). Several ABC transporters, such as ABCB1 (P-glycoprotein), ABCC5 (MRP5), or ABCC9 (SUR2), are present in the human heart (Solbach et al., 2006). These transporters are involved in lipid metabolism and movement, as well as cardiomyocyte function via cyclic nucleotide efflux and metabolism, homeostasis, and potentially xenobiotic movement (Ichikawa et al., 2012; Schumacher and Benndorf, 2017).

One of the best characterized ABC transporters is P-glycoprotein, also known as P-gp or multidrug resistance protein 1 (MDR1), the product of ABCB 1 gene. P-gp is a drug efflux pump to protect the organism against toxic xenobiotic compounds. In the human heart, P-gp has been identified at both the mRNA and protein levels in endothelial cells of cardiac arterioles and capillaries. P-gp expression was greatly reduced in samples from dilated cardiomyopathy hearts (Meissner et al., 2002). Variable P-gp expressions were reported from human heart tissues (Meissner et al., 2004). Digoxin has been demonstrated to be a substrate for $\mathrm{P}$-gp, as well as the $\beta$-adrenergic antagonists talinolol and celiprolol (Karlsson et al., 1993; Westphal et al., 2000). Overexpression of P-gp has also been associated with multiple drug resistance, as well as decreased cytotoxicity of agents such as anthracycline chemotherapeutics (Krishna and Mayer, 2000; Zhou et al., 2016). Individual variability of expression of this transporter is a possible explanation for variable response to substrates.

The multidrug resistance protein 5 (MRP5/ABCC5) has been localized to the heart, in terms of both mRNA and protein expression. Using samples from adult humans presenting either for bypass surgery or transplantation, MRP5 was identified in three different cardiac cell types: vascular smooth muscle cells, cardiomyocytes, and vascular endothelial cells. MRP5 mediates the cellular efflux of $3^{\prime}, 5^{\prime}$-cyclic nucleotides, cAMP, and cGMP. Therefore, it is suggested that MRP5 can affect NO/cGMP signaling by reducing its intracellular content in addition to its metabolic degradation by phosphodiesterases. Greater expression of MRP5 was observed in the ischemic cardiomyopathy

TABLE 7

Metabolic components identified in canine heart

\begin{tabular}{|c|c|c|}
\hline \multicolumn{2}{|c|}{ Component } & \multirow[b]{2}{*}{ Coppen et al., 1999,2001} \\
\hline Connexins & $\mathrm{Cx} 45$ & \\
\hline Area composita and ID & Prolonged development after birth & Angst et al., 1997 \\
\hline P450 & CYP4A, 4F, 4A37, 4A38, 4A39 & Graham et al., 2006; Aliwarga et al., 2018 \\
\hline Glucose related & GLUT4 & Ware et al., 2011 \\
\hline
\end{tabular}

ID, intercalcated disk; P450, cytochrome P450. 
tissues compared with the normal ventricular samples (Dazert et al., 2003).

In addition to chemical excretion, $\mathrm{ABC}$ transporters also play important roles in heart development, including the shift from fetal glycolytic to postnatal mitochondrial oxidative metabolism. For example, SUR2 (encoded by ABCC9) is a regulatory subunit of the major potassium-sensitive ATP $\left(\mathrm{K}_{\mathrm{ATP}}\right)$ channel in the heart. SUR2-containing $\mathrm{K}_{\mathrm{ATP}}$ channels are enriched in the sarcolemma, where they control opening or closing of the potassium channel in response to the intracellular energy state. When Abcc9, the gene coding for ABCC9, is deleted from mice, the period from postnatal day 2 to postnatal day 8 is marked by a failure to develop adequate mitochondrial networks to support cardiac growth. These animals develop a fatal neonatal cardiomyopathy (Fahrenbach et al., 2014).

\section{Energy Metabolism}

Continuous work means the heart requires a continuous energy supply. It is estimated that approximately $60 \%-70 \%$ of the ATP generated in the heart is consumed in contraction, and the remaining $30 \%-40 \%$ is consumed by the sarcoendoplasmic reticulum calcium transport ATPase and other ion pumps (Schramm et al., 1994; Stanley et al., 2005). The profound energy demand makes this aspect of cardiac metabolism one where even small disruptions or alterations may have significant consequences. This is also an area of intense study for the connection to heart failure and cardiomyopathies.

The mammalian fetal heart generates most of its ATP from glycolysis and lactate oxidation. In the newborn human, almost half of total ATP is produced from glycolysis. In the mature human heart, glucose generates approximately $25 \%-30 \%$ of total energy. The postnatal energy transition is from glucose metabolism to fatty acids and mitochondrial oxidative metabolism (reviewed in Onay-Besikci (2006)). The time frame of this transition is described for several species. Early work by Breuer et al. $(1967,1968)$ suggested that from 7 to 12 days after birth and from 13 to 21 days after birth, dogs had different cardiac metabolic profiles from each other and from adult dogs, based on determination of glucose, lactate, and pyruvate from coronary arterial and venous blood flow (Breuer et al., 1967). Follow-up studies on puppies from 7 to 13 days of age and a second group from 13 to 28 days of age suggested that the change from use of carbohydrates to use of fatty acids occurs at approximately the 14th day of life in dogs. Also, in the third week of life, the heart changed from lactate release to lactate uptake, coinciding with the beginning of free fatty acid uptake (Breuer et al., 1968). In rabbits, the contribution of glycolysis decreases from $44 \%$ on day 1 to approximately $10 \%$ of total cardiac ATP by day 7 after birth, similar to production in an adult human heart (Lopaschuk et al., 1991). Consistent with the decrease in glycolysis, isolated rabbit heart preparations demonstrated fatty acids as the main source of energy by 2 weeks of age (Itoi and Lopaschuk, 1993). Newborn rabbits with volume overload-induced hypertrophy had fatty acid oxidation rates $60 \%$ lower than control animals, and glycolysis rates increased by $246 \%(P<0.05)$. Overall, ATP production was significantly lower in the hypertrophied rabbit hearts (Oka et al., 2012).

Growing/proliferating cells are usually characterized by immaturity of both the mitochondria and the mitochondrial networks (Lopaschuk and Jaswal, 2010; Tuomainen and Tavi, 2017). The endogenous metabolic development of the heart after birth includes a surge of mitochondrial biogenesis, followed by mitochondrial maturation, redistribution, and packing of mature mitochondria along myofibrils. This stage of maturation includes increases in the processes of mitophagy (selective autophagous degradation of mitochondria), fusion, and fission (Dorn et al., 2015). Ultimately, postnatal development of cardiac energy production depends on mitochondrial maturation, with a complex interrelationship with the cardiac EETs (Singh et al., 2016).

Another aspect of cardiac energy metabolism is the availability of substrate. Two classes of glucose transporters have been identified in the human heart: GLUTs (facilitative glucose transporters) and SGLTs (sodium-glucose cotransporters) (reviewed in Szablewski (2017)).

GLUT1 and GLUT4 have been identified in the rat heart. During fetal life of rats, GLUT1 (encoded by SLC2A1 and a member of the major facilitator superfamily) and hexokinase I are the predominant glucose transporters present in rat hearts. Soon after birth in the rat, cardiac GLUT1/hexokinase I expression decreased, whereas after postnatal day 10, GLUT4 and hexokinase II expression increased (Wang and Hu, 1991; Santalucía et al., 1992). The insulin-sensitive GLUT4 represents $70 \%$ of the glucose transporters in an adult human heart, with GLUT1 the next most prominent transporter. In resting (low insulin) conditions, GLUT4 is located primarily in intracellular membrane compartments. Stimuli such as ischemia, catecholamines, or insulin will cause acute translocation of GLUT4 to the cell surface, without transcription or translation, increasing glucose transport into cardiomyocytes by as much as 10 - to 20-fold, as demonstrated in isolated rat cardiomyocytes, hearts of diabetic swine, and nondiabetic dogs (Stanley et al., 1994; Fischer et al., 1996; Brosius et al., 1997a; Young et al., 1997; Mueckler and Thorens, 2013). Expression of GLUT4 is also influenced by fatty acids and thyroid hormone (Gosteli-Peter et al., 1996; Finck et al., 2002). A study in adult dogs indicated a greater protein distribution of GLUT4 in atria compared with ventricles. During chronic heart failure in dogs induced by pacing, GLUT4 protein content was highest in the left ventricle while the amount in the right atrium was decreased (Ware et al., 2011).

GLUTs1, 3, 8, 10, 11, and 12 have also been identified in the adult human heart; however, characterization of their physiologic roles is incomplete. Transcriptional regulation has been determined to be the main mechanism for expression and activity of these molecules in the heart. GLUT1 in an adult may account for up to $40 \%$ of glucose transport, regulated by chronic hypoxia and long-term fasting (Kraegen et al., 1993; Brosius et al., 1997b). GLUT3 has been identified in both fetal and adult human hearts (Kayano et al., 1988; Grover-McKay et al., 1999). The function of GLUT8 is unclear, but it has been identified in the mouse heart, along with lower levels of GLUT3, GLUT10, and GLUT12. Studies in paced mice given a longterm high-fat diet suggest a role in regulating atrial activity (AerniFlessner et al., 2012; Maria et al., 2018). GLUT11 transports both glucose and fructose. This transporter has three splice variants, differentially expressed in heart, skeletal muscle, kidney, adipose tissue, and pancreas (Doege et al., 2001; Scheepers et al., 2005). GLUT10 (SLC2A10) also has wide tissue distribution beyond the heart. Homozygous mutation of the SLC2A10 gene is linked to a disorder called arterial tortuosity syndrome, in which morphologic abnormalities of the arteries are present. Like other GLUTs, GLUT12 is present in heart and skeletal muscle, as well as prostate and small intestine. In healthy and diabetic mouse hearts, no difference was seen in total GLUT12. Under the conditions of this study, GLUT12 translocation did not appear to be insulin-responsive, unlike GLUT4 (Waller et al., 2013).

The SGLT exists in several isoforms. The SGLT1 isoform is expressed in the small intestine, renal proximal tubule, and heart (Turk et al., 1991; Zhou et al., 2003). The SGLT1 was expressed in healthy human and murine myocardial tissue and significantly 
upregulated in diabetes mellitus, ischemia, and hypertrophy (Banerjee et al., 2009; Di Franco et al., 2017).

\section{Discussion and Conclusion}

The heart contains metabolic machinery for processing endogenous material for energy production, physiologic development, and homeostasis. The same machinery can also transport and process xenobiotics. The mitochondrial and nuclear regulation of these pathways is intricately connected and incompletely understood. The intricacy of metabolic machinery is made more complex when genetic variants of the components are considered. We found little information about the postnatal development of cardiac metabolism, exception for energy processes. Other than energy metabolism, little information was found about ontogeny, time to full or mature function, and species differences. The last data gap is not surprising as much of the current information has been generated in human tissues. The limitation to this is that most of these human studies have had small sample sizes and tend to be from mature or aged hearts. The data from nonhuman species included some information about development of metabolic machinery for energy production but leave gaps primarily for transporters, phase 1 , and phase 2 metabolism.

The relatively new concept of protein partners for coordination and communication of effects of receptors and transporters between distant sites is an intriguing one. Conceptually, it fits with an emerging systems biology view of receptors and transporters having roles in metabolite signaling pathways, interorgan communication, as well as neuroendocrine, growth factor, and general homeostatic processes (Nigam, 2018), and links development of local metabolic capability with the regulation of protein isoform shifts. The signaling pathways for both these phenomena, as well as the potential connections between the two, are incompletely described.

A detailed understanding of cross-species cardiac metabolism offers several possibilities (Tables 4, 5, 6, and 7). First, it may be possible to leverage local metabolic capabilities to create location-specific conversion of prodrugs to active moieties. Second, an understanding of the natural progression of ontogeny, followed by mature function and then physiologic deterioration, may assist in understanding the differences in drug effects between adults and children in general and special disease populations within age groups. With greater understanding of species similarities both in composition and ontogeny, it may be possible to design more informative nonclinical studies.

It seems intuitive that there may be developmental periods sensitive to xenobiotic perturbation or pathways susceptible at any age to chemical disruption. Although some information is available about pharmaceuticals that were substrates or inhibitors for cardiac enzymes or transporters, little characterization of downstream effects or effects on signaling pathways was found, which has relevance for pediatric therapeutics: disruption of normal developmental pathways. Effects on cardiac function, reaching full adult cardiovascular capacity, or increased susceptibility to different forms of cardiovascular disease may not be perceptible for years to decades after exposure to a drug. By that time, many confounding factors have entered the picture. The same information about downstream effects on signaling pathways may also be informative for conditions such as heart failure. Events and signaling pathways unique to different ages (e.g., adult or geriatric) or physiologic stages may help to identify sensitive developmental windows and, further, to avoid unintended or adverse effects, such as acceleration of naturally occurring cardiovascular disease.

Important areas for further exploration are cardiac metabolism related to drug toxicity, or targeted therapeutics, involvement in normal postnatal development, and modulation of adult homeostasis. We found some descriptions of cardiac-specific metabolism in the literature, but this is clearly an emerging area of research in both therapeutics and toxicity. The possible association of xenobiotic modulation of postnatal development seems to be largely undescribed. In this area, greater understanding of postnatal ontogeny becomes an issue of translational significance. Studies using human tissue have produced information for several disease states; however, sample sizes tend to be small, and it is unclear how much the results can be extrapolated to the population in general, given the genetic diversity of humans.

Comparisons of species effects, or translational value, were similarly limited; direct interspecies comparisons are rare. Differences between both species, breeds within species and strains within breeds have been demonstrated. Studying postnatal development in different animal species is already complicated by the brevity of various physiologic windows and, in some cases, lack of similarity of the general developmental stage to the equivalent human developmental stage. Ideally, hypothesis-driven studies could be designed with an understanding of species differences, thus maximizing the translational value of the work. At this time, it is not possible or realistic to make generic recommendations of nonhuman species for investigative work or safety assessment based on the available information. Clearly, understanding the postnatal ontogeny of metabolism overall has the potential to significantly impact the development of pediatric therapeutics.

\section{Acknowledgments}

This review is part of an effort of several working groups coordinated by the Health and Environmental Sciences Institute to identify, compile, and integrate information concerning the postnatal development of various body systems, with emphasis on metabolism, the coordinated processes encompassing absorption, distribution, transformation (metabolism), and excretion (De Schaepdrijver et al., 2018). This working group is composed of members from the federal government, industry, and academic communities. This work was supported [in part] by the NIH, National Institute of Environmental Health Sciences.

\section{Authorship Contributions}

Wrote or contributed to the writing of the manuscript: Hausner, Elmore, Yang.

\section{References}

Aerni-Flessner L, Abi-Jaoude M, Koenig A, Payne M, and Hruz PW (2012) GLUT4, GLUT1, and GLUT8 are the dominant GLUT transcripts expressed in the murine left ventricle. Cardiovasc Diabetol 11:63-88.

Aird WC (2007) Phenotypic heterogeneity of the endothelium: II. Representative vascular beds. Circ Res 100:174-190.

Aliwarga T, Evangelista EA, Sotoodehnia N, Lemaitre RN, and Totah RA (2018) Regulation of CYP2J2 and EET levels in cardiac disease and diabetes. Int J Mol Sci 19:1916. DOI:10.3390/ ijms 19071916.

Alnouti Y and Klaassen CD (2006) Tissue distribution and ontogeny of sulfotransferase enzymes in mice. Toxicol Sci 93:242-255.

Alnouti Y and Klaassen CD (2011) Mechanisms of gender-specific regulation of mouse sulfotransferases (Sults). Xenobiotica 41:187-197.

Angst BD, Khan LUR, Severs NJ, Whitely K, Rothery S, Thompson RP, Magee AI, and Gourdie RG (1997) Dissociated spatial patterning of gap junctions and cell adhesion junctions during postnatal differentiation of ventricular myocardium. Circ Res 80:88-94.

Arnold WR, Weigle AT, and Das A (2018) Cross-talk of cannabinoid and endocannabinoid metabolism is mediated via human cardiac CYP2J2. J Inorg Biochem 184:88-99.

Askari A, Thomson SJ, Edin ML, Zeldin DC, and Bishop-Bailey D (2013) Roles of the epoxygenase CYP2J2 in the endothelium. Prostaglandins Other Lipid Mediat 107:56-63.

Aspromonte N, Monitillo F, Puzzovivo A, Valle R, Caldarola P, and Iacoviello M (2014) Modulation of cardiac cytochrome P450 in patients with heart failure. Expert Opin Drug Metab Toxicol 10:327-339.

Atilano-Roque A and Joy MS (2017) Characterization of simvastatin acid uptake by organic anion transporting polypeptide 3A1 (OATP3A1) and influence of drug-drug interaction. Toxicol In Vitro 45:158-165.

Banerjee SK, McGaffin KR, Pastor-Soler NM, and Ahmad F (2009) SGLT1 is a novel cardiac glucose transporter that is perturbed in disease states. Cardiovasc Res 84:111-118.

Barker DF, Walraven JM, Ristagno EH, Doll MA, States JC, and Hein DW (2008) Quantitative tissue and gene-specific differences and developmental changes in Nat1, Nat2, and Nat3 mRNA expression in the rat. Drug Metab Dispos 36:2445-2451. 
Barreto-Chaves MLM, Carrillo-Sepúlveda MA, Carneiro-Ramos MS, Gomes DA, and Diniz GP (2010) The crosstalk between thyroid hormones and the renin-angiotensin system. Vascul Pharmacol 52:166-170.

Bastide B, Neyses L, Ganten D, Paul M, Willecke K, and Traub O (1993) Gap junction protein connexin 40 is preferentially expressed in vascular endothelium and conductive bundles of rat myocardium and is increased under hypertensive conditions. Circ Res 73:1138-1149.

Bazzoni G and Dejana E (2004) Endothelial cell-to-cell junctions: molecular organization and role in vascular homeostasis. Physiol Rev 84:869-901.

Bennett PM, Maggs AM, Baines AJ, and Pinder JC (2006) The transitional junction: a new functional subcellular domain at the intercalated disc. Mol Biol Cell 17:2091-2100.

Boengler K, Dodoni G, Rodriguez-Sinovas A, Cabestrero A, Ruiz-Meana M, Gres P, Konietzka I, Lopez-Iglesias C, Garcia-Dorado D, Di Lisa F, et al. (2005) Connexin 43 in cardiomyocyte mitochondria and its increase by ischemic preconditioning. Cardiovasc Res 67:234-244.

Borrmann CM, Grund C, Kott M, Morano I, and Franke WW (1999) Identification of a novel type of adhering junction (area composite) in heart cells (Abstract). Eur J Cell Biol 78 (Suppl 49):34

Breuer E, Barta E, Pappová E, and Zlatoś L (1967) Developmental changes of myocardial metabolism. I. Peculiarities of cardiac carbohydrate metabolism in the early postnatal period in dogs. Biol Neonat 11:367-377.

Breuer E, Barta E, Zlatoś L, and Pappová E (1968) Developmental changes of myocardial metabolism. II. Myocardial metabolism of fatty acids in the early postnatal period in dogs. Biol Neonat 12:54-64.

Brosius FC III, Liu Y, Ngyuen N, Sun D, and Schwaiger M (1997b) Persistent myocardial ischemia increases GLUT1 glucose transporter expression in both ischemic and non-ischemic heart regions. J Mol Cell Cardiol 29:1675-1685.

Brosius FC III, Ngyuen N, Egert S, Lin Z, Deeb GM, Haas F, Schwaiger M, and Sun D (1997a) Increased sarcolemmal glucose transporter abundance in myocardial ischemia. Am J Cardiol 80: 77A-84A.

Brownsey RW, Boone AN, and Allard MF (1997) Actions of insulin on the mammalian heart: metabolism, pathology and biochemical mechanisms. Cardiovasc Res 34:3-24.

Bylund J, Bylund M, and Oliw EH (2001) cDna cloning and expression of CYP4F12, a novel human cytochrome P450. Biochem Biophys Res Commun 280:892-897.

Carballo S, Pfenniger A, Carballo D, Garin N, James RW, Mach F, Shah D, and Kwak BR (2018) Differential association of $\mathrm{Cx} 37$ and $\mathrm{Cx} 40$ genetic variants in atrial fibrillation with and without underlying structural heart disease. Int J Mol Sci 19. DOI: 10.3390/ijms19010295.

Cardona A, Baker P, Kahwash R, Smart S, Phay JE, Basso C, and Raman SV (2019) Evidence of aldosterone synthesis in human myocardium in acute myocarditis. Int J Cardiol 275:114-119.

Chattergoon NN, Giraud GD, Louey S, Stork P, Fowden AL, and Thornburg KL (2012) Thyroid hormone drives fetal cardiomyocyte maturation. FASEB J 26:397-408.

Chaudhary KR, Batchu SN, and Seubert JM (2009) Cytochrome P450 enzymes and the heart. IUBMB Life 61:954-960.

Choudhary D, Jansson I, Schenkman JB, Sarfarazi M, and Stoilov I (2003) Comparative expression profiling of 40 mouse cytochrome $\mathrm{P} 450$ genes in embryonic and adult tissues. Arch Biochem Biophys 414:91-100.

Chen J, Zheng H, Zeng S, Xie C, Li X, Yan T, Gong X, Lu L, Qi X, Wang Y, et al. (2017) Profiles and gender-specifics of UDP-glucuronosyltransferases and sulfotransferases expressions in the major metabolic organs of wild-type and efflux transporter knockout FVB mice. Mol Pharm 14 2967-2976.

Chen S, Beaton D, Nguyen N, Senekeo-Effenberger K, Brace-Sinnokrak E, Argikar U, Remmel RP, Trottier J, Barbier O, Ritter JK, et al. (2005) Tissue-specific, inducible, and hormonal control of the human UDP-glucuronosyltransferase-1 (UGT1) locus. J Biol Chem 280:37547-37557.

Chen S-C, Davis LM, Westphale EM, Beyer EC, and Saffitz JE (1994) Expression of multiple gap junction proteins in human fetal and infant hearts. Pediatr Res 36:561-566.

Collins JM (2001) Inter-species differences in drug properties. Chem Biol Interact 134:237-242.

Coppen SR, Dupont E, Rothery S, and Severs NJ (1998) Connexin45 expression is preferentially associated with the ventricular conduction system in mouse and rat heart. Circ Res 82:232-243.

Coppen SR, Gourdie RG, and Severs NJ (2001) Connexin 45 is the first connexin to be expressed in the central conduction system of the mouse heart. Exp Clin Cardiol 6:17-23.

Coppen SR, Kodama I, Boyett MR, Dobrzynski H, Takagishi Y, Honjo H, Yeh H-I, and Severs NJ (1999) Connexin45, a major connexin of the rabbit sinoatrial node, is co-expressed with connexin 43 in a restricted zone at the nodal-crista terminalis border. J Histochem Cytochem 47: 907-918.

Court MH, Zhang X, Ding X, Yee KK, Hesse LM, and Finel M (2012) Quantitative distribution of mRNAs encoding the 19 human UDP-glucuronosyltransferase enzymes in 26 adult and 3 fetal tissues. Xenobiotica 42:266-277.

Dazert P, Meissner K, Vogelgesang S, Heydrich B, Eckel L, Böhm M, Warzok R, Kerb R, Brinkmann U, Schaeffeler E, et al. (2003) Expression and localization of the multidrug resistance protein 5 (MRP5/ABCC5), a cellular export pump for cyclic nucleotides, in human heart. Am J Pathol 163:1567-1577.

Dejana E (2004) Endothelial cell-cell junctions: happy together. Nat Rev Mol Cell Biol 5:261-270.

Delozier TC, Kissling GE, Coulter SJ, Dai D, Foley JF, Bradbury JA, Murphy E, Steenbergen C, Zeldin DC, and Goldstein JA (2007) Detection of human CYP2C8, CYP2C9, and CYP2J2 in cardiovascular tissues. Drug Metab Dispos 35:682-688.

Deng Y, Theken KN, and Lee CR (2010) Cytochrome P450 epoxygenases, soluble epoxide hydrolase, and the regulation of cardiovascular inflammation. J Mol Cell Cardiol 48:331-341.

De Vuyst E, Boengler K, Antoons G, Sipido KR, Schulz R, and Leybaert L (2011) Pharmacological modulation of connexin-formed channels in cardiac pathophysiology. Br J Pharmacol 163:469-483.

de Wit C and Griffith TM (2010) Connexins and gap junctions in the EDHF phenomenon and conducted vasomotor responses. Pflugers Arch 459:897-914.

Di Franco A, Cantini G, Tani A, Coppini R, Zecchi-Orlandini S, Raimondi L, Luconi M, and Mannucci E (2017) Sodium-dependent glucose transporters (SGLT) in human ischemic heart: a new potential pharmacological target. Int J Cardiol 243:86-90.

Dillmann W (2010) Cardiac hypertrophy and thyroid hormone signaling. Heart Fail Rev 15: $125-132$.

Dunn RT II and Klaassen CD (1998) Tissue-specific expression of rat sulfotransferase messenger RNAs. Drug Metab Dispos 26:598-604.

Doege H, Bocianski A, Scheepers A, Axer H, Eckel J, Joost H-G, and Schürmann A (2001) Characterization of human glucose transporter (GLUT) 11 (encoded by SLC2A11), a novel sugar-transport facilitator specifically expressed in heart and skeletal muscle. Biochem J 359: 443-449.
Dolmatova E, Spagnol G, Boassa D, Baum JR, Keith K, Ambrosi C, Kontaridis MI, Sorgen PL, Sosinsky GE, and Duffy HS (2012) Cardiomyocyte ATP release through pannexin 1 aids in early fibroblast activation. Am J Physiol Heart Circ Physiol 303:H1208-H1218.

Dong F, Yang XJ, Jiang TB, and Chen Y (2016) Ischemia triggered ATP release through Pannexin-1 channel by myocardial cells activates sympathetic fibers. Microvasc Res 104 32-37.

Dorn GW II, Vega RB, and Kelly DP (2015) Mitochondrial biogenesis and dynamics in the developing and diseased heart. Genes Dev 29:1981-1991.

El-Sherbeni AA, Aboutabl ME, Zordoky BN, Anwar-Mohamed A, and El-Kadi AO (2013) Determination of the dominant arachidonic acid cytochrome p450 monooxygenases in rat heart, lung, kidney, and liver: protein expression and metabolite kinetics. AAPS J 15:112-122.

Fahrenbach JP, Stoller D, Kim G, Aggarwal N, Yerokun B, Earley JU, Hadhazy M, Shi N-Q, Makielski JC, and McNally EM (2014) Abcc9 is required for the transition to oxidative metabolism in the newborn heart. FASEB J 28:2804-2815.

Finck BN, Lehman JJ, Leone TC, Welch MJ, Bennett MJ, Kovacs A, Han X, Gross RW, Kozak R, Lopaschuk GD, et al. (2002) The cardiac phenotype induced by PPARalpha overexpression mimics that caused by diabetes mellitus. J Clin Invest 109:121-130.

Fischer Y, Thomas J, Holman GD, Rose H, and Kammermeier H (1996) Contraction-independent effects of catecholamines on glucose transport in isolated rat cardiomyocytes. Am J Physiol 270 C1204-C1210.

Forbes MS and Sperelakis N (1985) Intercalated discs of mammalian heart: a review of structure and function. Tissue Cell 17:605-648.

Franke WW, Borrmann CM, Grund C, and Pieperhoff S (2006) The area composita of adhering junctions connecting heart muscle cells of vertebrates. I. Molecular definition in intercalated disks of cardiomyocytes by immunoelectron microscopy of desmosomal proteins. Eur J Cell Biol 85:69-82.

Fujiwara K, Adachi H, Nishio T, Unno M, Tokui T, Okabe M, Onogawa T, Suzuki T, Asano N, Tanemoto M, et al. (2001) Identification of thyroid hormone transporters in humans: different molecules are involved in a tissue-specific manner. Endocrinology 142:2005-2012.

Gaedigk A, Baker DW, Totah RA, Gaedigk R, Pearce RE, Vyhlidal CA, Zeldin DC, and Leeder JS (2006) Variability of CYP2J2 expression in human fetal tissues. J Pharmacol Exp Ther 319: 523-532.

Ganapathy ME, Huang W, Rajan DP, Carter AL, Sugawara M, Iseki K, Leibach FH, and Ganapathy V (2000) $\beta$-lactam antibiotics as substrates for OCTN2, an organic cation/ carnitine transporter. J Biol Chem 275:1699-1707.

Gemel J, Levy AE, Simon AR, Bennett KB, Ai X, Akhter S, and Beyer EC (2014) Connexin40 abnormalities and atrial fibrillation in the human heart. $J$ Mol Cell Cardiol 76:159-168.

Gervasini G, Carrillo JA, and Benitez J (2004) Potential role of cerebral cytochrome P450 in clinical pharmacokinetics: modulation by endogenous compounds. Clin Pharmacokinet $\mathbf{4 3}$ 693-706.

Ghaffari T, Nouri M, Saei AA, and Rashidi M-R (2012) Aldehyde and xanthine oxidase activities in tissues of streptozotocin-induced diabetic rats: effects of vitamin $\mathrm{E}$ and selenium supplementation. Biol Trace Elem Res 147:217-225.

Gosteli-Peter MA, Schmid C, and Zapf J (1996) Triiodothyronine increases glucose transporter isotype 4 mRNA expression, glucose transport, and glycogen synthesis in adult rat cardiomyocytes in long-term culture. Biochem Biophys Res Commun 221:521-524.

Gourdie RG, Severs NJ, Green CR, Rothery S, Germroth P, and Thompson RP (1993) The spatial distribution and relative abundance of gap-junctional connexin 40 and connexin 43 correlate to functional properties of components of the cardiac atrioventricular conduction system. J Cell Sci 105:985-991.

Graham RA, Goodwin B, Merrihew RV, Krol WL, and Lecluyse EL (2006) Cloning, tissue expression, and regulation of beagle dog CYP4A genes. Toxicol Sci 92:356-367.

Grais IM and Sowers JR (2014) Thyroid and the heart. Am J Med 127:691-8.

Grikscheit K, Thomas N, Bruce AF, Rothery S, Chan J, Severs NJ, and Dupont E (2008) Coexpression of connexin 45 with connexin 43 decreases gap junction size. Cell Commun Adhes 15: $185-193$.

Gros DB and Jongsma HJ (1996) Connexins in mammalian heart function. BioEssays 18:719-730 Grover-McKay M, Walsh SA, and Thompson SA (1999) Glucose transporter 3 (GLUT3) protein is present in human myocardium. Biochim Biophys Acta 1416:145-154

Grube M, Ameling S, Noutsias M, Köck K, Triebel I, Bonitz K, Meissner K, Jedlitschky G, Herda LR, Reinthaler M, et al. (2011) Selective regulation of cardiac organic cation transporter novel type 2 (OCTN2) in dilated cardiomyopathy. Am J Pathol 178:2547-2559.

Grube M, Köck K, Oswald S, Draber K, Meissner K, Eckel L, Böhm M, Felix SB, Vogelgesang S, Jedlitschky G, et al. (2006) Organic anion transporting polypeptide 2B1 is a high-affinity transporter for atorvastatin and is expressed in the human heart. Clin Pharmacol Ther 80: $607-620$.

Gründemann D, Koschker AC, Haag C, Honold C, Zimmermann T, and Schömig E (2002) Activation of the extraneuronal monoamine transporter (EMT) from rat expressed in 293 cells Br J Pharmacol 137:910-918.

Hagenbuch B and Meier PJ (2003) The superfamily of organic anion transporting polypeptides. Biochim Biophys Acta 1609:1-18.

Helke KL and Swindle MM (2013) Animal models of toxicology testing: the role of pigs. Expert Opin Drug Metab Toxicol 9:127-139.

Henderson CA, Gomez CG, Novak SM, Mi-Mi L, and Gregorio CC (2017) Overview of the muscle cytoskeleton. Compr Physiol 7:891-944.

Hsieh PCH, Davis ME, Lisowski LK, and Lee RT (2006) Endothelial-cardiomyocyte interactions in cardiac development and repair. Annu Rev Physiol 68:51-66.

Huber RD, Gao B, Sidler Pfändler MA, Zhang-Fu W, Leuthold S, Hagenbuch B, Folkers G, Meier PJ, and Stieger B (2007) Characterization of two splice variants of human organic anion transporting polypeptide 3A1 isolated from human brain. Am J Physiol Cell Physiol 292: C795-C806.

Ichikawa Y, Bayeva M, Ghanefar M, Potini V, Sun L, Mutharasan RK, Wu R, Khechaduri A, Jaira Naik T, and Ardehali H (2012) Disruption of ATP-binding cassette B8 in mice leads to cardiomyopathy through a decrease in mitochondrial iron export. Proc Natl Acad Sci USA 109: $4152-4157$.

Itoi T and Lopaschuk GD (1993) The contribution of glycolysis, glucose oxidation, lactate oxidation, and fatty acid oxidation to ATP production in isolated biventricular working hearts from 2-week-old rabbits. Pediatr Res 34:735-741.

Iversen LL (1965) The uptake of catechol amines at high perfusion concentrations in the rat isolated heart: a novel catechol amine uptake process. Br J Pharmacol Chemother 25:18-33. 
Iwata D, Kato Y, Wakayama T, Sai Y, Kubo Y, Iseki S, and Tsuji A (2008) Involvement of carnitine/organic cation transporter OCTN2 (SLC22A5) in distribution of its substrate carnitine to the heart. Drug Metab Pharmacokinet 23:207-215.

Jamieson KL, Endo T, Darwesh AM, Samokhvalov V, and Seubert JM (2017) Cytochrome P450derived eicosanoids and heart function. Pharmacol Ther 179:47-83.

Jancova P, Anzenbacher P, and Anzenbacherova E (2010) Phase II drug metabolizing enzymes. Biomed Pap Med Fac Univ Palacky Olomouc Czech Repub 154:103-116.

Jensen KG, Jacobsen A-M, Bundgaard C, Nilausen D $\varnothing$, Thale Z, Chandrasena G, and Jørgensen M (2017) Lack of exposure in a first-in-man study due to aldehyde oxidase metabolism: in vestigated by use of ${ }^{14} \mathrm{C}$-microdose, humanized mice, monkey pharmacokinetics, and in vitro methods. Drug Metab Dispos 45:68-75.

Johansen D, Cruciani V, Sundset R, Ytrehus K, and Mikalsen SO (2011) Ischemia induces closure of gap junctional channels and opening of hemichannels in heart-derived cells and tissue. Cell Physiol Biochem 28:103-114.

Jonker SS and Louey S (2016) Endocrine and other physiologic modulators of perinatal cardiomyocyte endowment. $J$ Endocrinol 228:R1-R18

Jovic M, Stancic A, Nenadic D, Cekic O, Nezic D, Milojevic P, Micovic S, Buzadzic B, Korac A, Otasevic V, et al. (2012) Mitochondrial molecular basis of sevoflurane and propofol cardioprotection in patients undergoing aortic valve replacement with cardiopulmonary bypass. $\mathrm{Cell}$ Physiol Biochem 29:131-142.

Kamo S, Nakanishi T, Aotani R, Nakamura Y, Gose T, and Tamai I (2017) Impact of FDAapproved drugs on the prostaglandin transporter OATP2A1/SLCO2A1. J Pharm Sci 106: 2483-2490.

Kanter HL, Laing JG, Beyer EC, Green KG, and Saffitz JE (1993) Multiple connexins colocalize in canine ventricular myocyte gap junctions. Circ Res 73:344-350.

Karlsson J, Kuo SM, Ziemniak J, and Artursson P (1993) Transport of celiprolol across human intestinal epithelial (Caco-2) cells: mediation of secretion by multiple transporters including P-glycoprotein. Br J Pharmacol 110:1009-1016.

Katz MG, Fargnoli AS, and Bridges CR (2013) Myocardial gene transfer: routes and devices for regulation of transgene expression by modulation of cellular permeability. Hum Gene Ther 24: 375-392.

Kayano T, Fukumoto H, Eddy RL, Fan YS, Byers MG, Shows TB, and Bell GI (1988) Evidence for a family of human glucose transporter-like proteins: sequence and gene localization of a protein expressed in fetal skeletal muscle and other tissues. J Biol Chem 263:15245-15248.

Kenessey A and Ojamaa K (2006) Thyroid hormone stimulates protein synthesis in the car diomyocyte by activating the Akt-mTOR and p70S6K pathways. J Biol Chem 281 20666-20672.

Kim K-H, Rosen A, Hussein SM, Puviindran V, Korogyi AS, Chiarello C, Nagy A, Hui C-C, and Backx PH (2016) Irx3 is required for postnatal maturation of the mouse ventricular conduction system. Sci Rep 6:19197.

King CD, Rios GR, Assouline JA, and Tephly TR (1999) Expression of UDP-glucuronosyltransferases (UGTs) 2B7 and 1A6 in the human brain and identification of 5-hydroxytryptamine as a substrate. Arch Biochem Biophys 365:156-162.

King LM, Ma J, Srettabunjong S, Graves J, Bradbury JA, Li L, Spiecker M, Liao JK, Mohrenweiser H, and Zeldin DC (2002) Cloning of CYP2J2 gene and identification of functional polymorphisms. Mol Pharmacol 61:840-852.

Koepsell H (2013) The SLC22 family with transporters of organic cations, anions and zwitterions. Mol Aspects Med 34:413-435.

Koepsell H, Lips K, and Volk C (2007) Polyspecific organic cation transporters: structure, function, physiological roles, and biopharmaceutical implications. Pharm Res 24:1227-1251.

Koren G (1997) Therapeutic drug monitoring principles in the neonate. National Academy of CLinical Biochemistry. Clin Chem 43:222-227.

Kraegen EW, Sowden JA, Halstead MB, Clark PW, Rodnick KJ, Chisholm DJ, and James DE (1993) Glucose transporters and in vivo glucose uptake in skeletal and cardiac muscle: fasting, insulin stimulation and immunoisolation studies of GLUT1 and GLUT4. Biochem J 295 287-293.

Krishna R and Mayer LD (2000) Multidrug resistance (MDR) in cancer. Mechanisms, reversal using modulators of MDR and the role of MDR modulators in influencing the pharmacokinetics of anticancer drugs. Eur J Pharm Sci 11:265-283.

Krüger M, Sachse C, Zimmermann WH, Eschenhagen T, Klede S, and Linke WA (2008) Thyroid hormone regulates developmental titin isoform transitions via the phosphatidylinositol-3-kinase/ AKT pathway. Circ Res 102:439-447.

Kuzman JA, Gerdes AM, Kobayashi S, and Liang Q (2005) Thyroid hormone activates Akt and prevents serum starvation-induced cell death in neonatal rat cardiomyocytes. J Mol Cell Cardiol 39: $841-844$.

Lafite P, Dijols S, Buisson D, Macherey AC, Zeldin DC, Dansette PM, and Mansuy D (2006) Design and synthesis of selective, high-affinity inhibitors of human cytochrome P450 2J2. Bioorg Med Chem Lett 16:2777-2780.

Lahrouchi N, Lodder EM, Mansouri M, Tadros R, Zniber L, Adadi N, Clur SB, van SpaendonckZwarts KY, Postma AV, Sefiani A, et al. (2017) Exome sequencing identifies primary carnitine deficiency in a family with cardiomyopathy and sudden death. Eur J Hum Genet 25:783-787.

Lamhonwah A-M and Tein I (2006) Novel localization of OCTN1, an organic cation/carnitine transporter, to mammalian mitochondria. Biochem Biophys Res Commun 345:1315-1325.

Lazard D, Tal N, Rubinstein M, Khen M, Lancet D, and Zupko K (1990) Identification an biochemical analysis of novel olfactory-specific cytochrome P-450IIA and UDP-glucuronosyl transferase. Biochemistry 29:7433-7440.

Lee CA, Neul D, Clouser-Roche A, Dalvie D, Wester MR, Jiang Y, Jones JP III, Freiwald S, Zientek M, and Totah RA (2010) Identification of novel substrates for human cytochrome P450 2J2. Drug Metab Dispos 38:347-356.

Lee SS, Jeong HE, Liu KH, Ryu JY, Moon T, Yoon CN, Oh SJ, Yun CH, and Shin JG (2005) Identification and functional characterization of novel CYP2J2 variants: G312R variant causes loss of enzyme catalytic activity. Pharmacogenet Genomics 15:105-113.

Lei M, Wu L, Terrar DA, and Huang CL-H (2018) Modernized classification of cardiac antiarrhythmic drugs. Circulation 138:1879-1896.

Li M, Lismaa SE, Nagyi N, Nicks A, Husain A, and Graham RM 2014 Thyroid hormone action in postnatal heart development. Stem Cell Res 13(3 Pt B):582-591.

Ling B, Aziz C, and Alcorn J (2012) Systematic evaluation of key L-carnitine homeostasis mechanisms during postnatal development in rat. Nutr Metab (Lond) 9:66-76.

Lopaschuk GD and Jaswal JS (2010) Energy metabolic phenotype of the cardiomyocyte during development, differentiation, and postnatal maturation. J Cardiovasc Pharmacol 56:130-140.
Lopaschuk GD, Spafford MA, and Marsh DR (1991) Glycolysis is predominant source of myocardial ATP production immediately after birth. Am J Physiol 261:H1698-H1705.

Lu R, Kanai N, Bao Y, and Schuster VL (1996) Cloning, in vitro expression, and tissue distribution of a human prostaglandin transporter cDNA(hPGT). J Clin Invest 98:1142-1149.

Luo H, Zhang Y, Guo H, Zhang L, Li X, Ringseis R, Wen G, Hui D, Liang A, Eder K, et al. (2014) Transcriptional regulation of the human, porcine and bovine OCTN2 gene by PPAR $\alpha$ via a conserved PPRE located in intron 1. BMC Genet 15:90.

Makowski L, Caspar DLD, Phillips WC, Baker TS, and Goodenough DA (1984) Gap junction structures. VI. Variation and conservation in connexon conformation and packing. Biophys $J \mathbf{4 5}$ : 208-218.

Maria Z, Campolo AR, Scherlag BJ, Ritchey JW, and Lacombe VA (2018) Dysregulation of insulin-sensitive glucose transporters during insulin resistance-induced atrial fibrillation. Biochim Biophys Acta Mol Basis Dis 1864(4 Pt A):987-996.

McBride BF, Yang T, Liu K, Urban TJ, Giacomini KM, Kim RB, and Roden DM (2009) The organic cation transporter, OCTN1, expressed in the human heart, potentiates antagonism of the HERG potassium channel. J Cardiovasc Pharmacol 54:63-71.

McDougle DR, Watson JE, Abdeen AA, Adili R, Caputo MP, Krapf JE, Johnson RW, Kilian KA, Holinstat M, and Das A (2017) Anti-inflammatory $\omega-3$ endocannabinoid epoxides. Proc Nat Acad Sci USA 114:E6034-E6043.

McGrath MF, de Bold ML, and de Bold AJ (2005) The endocrine function of the heart. Trends Endocrinol Metab 16:469-477.

Meens MJ, Kwak BR, and Duffy HS (2015) Role of connexins and pannexins in cardiovascular physiology. Cell Mol Life Sci 72:2779-2792.

Meissner K, Jedlitschky G, Meyer zu Schwabedissen H, Dazert P, Eckel L, Vogelgesang S, Warzok RW, Böhm M, Lehmann C, Wendt M, et al (2004) Modulation of multidrug resistance P-glycoprotein 1 (ABCB1) expression in human heart by hereditary polymorphisms. Pharmacogenetics 14:381-385.

Meissner K, Sperker B, Karsten C, Meyer Zu Schwabedissen H, Seeland U, Böhm M, Bien S, Dazert P, Kunert-Keil C, Vogelgesang S, et al. (2002) Expression and localization of P-glycoprotein in human heart: effects of cardiomyopathy. J Histochem Cytochem 50: 1351-1356.

Miro-Casas E, Ruiz-Meana M, Agullo E, Stahlhofen S, Rodríguez-Sinovas A, Cabestrero A, Jorge I, Torre I, Vazquez J, Boengler K, et al. (2009) Connexin43 in cardiomyocyte mitochondria contributes to mitochondrial potassium uptake. Cardiovasc Res 83:747-756.

Molina CE, Abu-Taha IH, Wang Q, Roselló-Díez E, Kamler M, Nattel S, Ravens U, Wehrens XHT, Hove-Madsen L, Heijman J, et al. (2018) Profibrotic, electrical, and calcium-handling remodeling of the atria in heart failure patients with and without atrial fibrillation. Front Physiol 9:1383.

Moscato S, Cabiati M, Bianchi F, Vaglini F, Morales MA, Burchielli S, Botta L, Sabbatini ARM Falleni A, Del Ry S, et al. (2018) Connexin 26 expression in mammalian cardiomyocytes. Sci Rep 8:13975.

Mueckler M and Thorens B (2013) The SLC2 (GLUT) family of membrane transporters. Mol Aspects Med 34:121-138.

Mueller JW, Gilligan LC, Idkowiak J, Arlt W, and Foster PA (2015) The regulation of steroid action by sulfation and desulfation. Endocr Rev 36:526-563.

Myhre JL and Pilgrim D (2014) A Titan but not necessarily a ruler: assessing the role of titin during thick filament patterning and assembly. Anat Rec (Hoboken) 297:1604-1614.

Nakamura T, Nakanishi T, Haruta T, Shirasaka Y, Keogh JP, and Tamai I (2010) Transport of ipratropium, an anti-chronic obstructive pulmonary disease drug, is mediated by organic cation/ carnitine transporters in human bronchial epithelial cells: implications for carrier-mediated pulmonary absorption. Mol Pharm 7:187-195.

Nebert DW, Wikvall K, and Miller WL (2013) Human cytochromes P450 in health and disease. Philos Trans $R$ Soc Lond B Biol Sci 368:20120431.

Nigam SK (2018) The SLC22 transporter family: a paradigm for the impact of drug transporters on metabolic pathways, signaling and disease. Апnи Rev Pharmacol Toxicol 58:663-687.

Nithipatikom K, Gross ER, Endsley MP, Moore JM, Isbell MA, Falck JR, Campbell WB, and Gross GJ (2004) Inhibition of cytochrome P450omega-hydroxylase: a novel endogenous cardioprotective pathway. Circ Res 95 :e65-e71.

Obaidat A, Roth M, and Hagenbuch B (2012) The expression and function of organic anion transporting polypeptides in normal tissues and in cancer. Annu Rev Pharmacol Toxicol 52: $135-151$.

Ock S, Lee WS, Ahn J, Kim HM, Kang H, Kim HS, Jo D, Abel ED, Lee TJ, and Kim J (2016) Deletion of IGF-1 receptors in cardiomyocytes attenuates cardiac aging in male mice. Endocrinology 157:336-345.

Oka T, Lam VH, Zhang L, Keung W, Cadete VJJ, Samokhvalov V, Tanner BA, Beker DL, Usshe JR, Huqi A, et al. (2012) Cardiac hypertrophy in the newborn delays the maturation of fatty acid $\beta$-oxidation and compromises postischemic functional recovery. Am J Physiol Heart Circ Physiol 302:H1784-H1794.

Ogawa T and de Bold AJ (2014) The heart as an endocrine organ. Endocr Connect 3:R31-R44. Okabe M, Szakács G, Reimers MA, Suzuki T, Hall MD, Abe T, Weinstein JN, and Gottesman MM (2008) Profiling SLCO and SLC22 genes in the NCI-60 cancer cell lines to identify drug uptake transporters. Mol Cancer Ther 7:3081-3091.

Onay-Besikci A (2006) Regulation of cardiac energy metabolism in newborn. Mol Cell Biochem 287:1-11

Oni-Orisan A, Edin ML, Lee JA, Wells MA, Christensen ES, Vendrov KC, Lih FB, Tomer KB, Bai X, Taylor JM, et al. (2016) Cytochrome P450-derived epoxyeicosatrienoic acids and coronary artery disease in humans: a targeted metabolomics study. J Lipid Res 57:109-119.

Palenski TL, Sorenson CM, Jefcoate CR, and Sheibani N (2013) Lack of Cyp1b1 promotes the proliferative and migratory phenotype of perivascular supporting cells. Lab Invest 93:646-662.

Pavek P and Dvorak Z (2008) Xenobiotic-induced transcriptional regulation of xenobiotic metabolizing enzymes of the cytochrome P450 superfamily in human extrahepatic tissues. Curr Drug Metab 9:129-143.

Peters NS, Severs NJ, Rothery SM, Lincoln C, Yacoub MH, and Green CR (1994) Spatiotemporal relation between gap junctions and fascia adherens junctions during postnatal development of human ventricular myocardium. Circulation 90:713-725.

Petric S, Klein S, Dannenberg L, Lahres T, Clasen L, Schmidt KG, Ding Z, and Donner BC (2016) Pannexin-1 deficient mice have an increased susceptibility for atrial fibrillation and show a QT-prolongation phenotype. Cell Physiol Biochem 38:487-501.

Pezzi V, Mathis JM, Rainey WE, and Carr BR (2003) Profiling transcript levels for steroidogenic enzymes in fetal tissues. J Steroid Biochem Mol Biol 87:181-189. 
Pieperhoff S, Borrmann C, Grund C, Barth M, Rizzo S, and Franke WW (2010) The area composita of adhering junctions connecting heart muscle cells of vertebrates. VII. The different types of lateral junctions between the special cardiomyocytes of the conduction system of ovine and bovine hearts. Eur J Cell Biol 89:365-378.

Pieperhoff S and Franke WW (2007) The area composita of adhering junctions connecting heart muscle cells of vertebrates - IV: coalescence and amalgamation of desmosomal and adhaerens junction components - late processes in mammalian heart development. Eur J Cell Biol 86: 377-391.

Poon IKH, Chiu Y-H, Armstrong AJ, Kinchen JM, Juncadella IJ, Bayliss DA, and Ravichandran KS (2014) Unexpected link between an antibiotic, pannexin channels and apoptosis. Nature 507: 329-334.

Ren S, Zeng J, Mei Y, Zhang JZ, Yan SF, Fei J, and Chen L (2013) Discovery and characterization of novel, potent, and selective cytochrome P450 2J2 inhibitors. Drug Metab Dispos 41:60-71.

Rhett JM and Gourdie RG (2012) The perinexus: a new feature of $\mathrm{Cx} 43$ gap junction organization. Heart Rhythm 9:619-623.

Rhett JM, Jourdan J, and Gourdie RG (2011) Connexin 43 connexon to gap junction transition is regulated by zonula occludens-1. Mol Biol Cell 22:1516-1528

Rhett JM, Veeraraghavan R, Poelzing S, and Gourdie RG (2013) The perinexus: sign-post on the path to a new model of cardiac conduction? Trends Cardiovasc Med 23:222-228.

Rodríguez-Sinovas A, Sanchez JA, Fernandez-Sanz C, Ruiz-Meana M, and Garcia-Dorado C (2012) Connexin and pannexin as modulators of myocardial injury. Biochim Biophys Acta 1818: 1962-1970

Roth M, Obaidat A, and Hagenbuch B (2012) OATPs, OATs and OCTs: the organic anion and cation transporters of the SLCO and SLC22A gene superfamilies. $\mathrm{Br} J$ Pharmacol 165: $1260-1287$.

Sakakibara Y, Yanagisawa K, Katafuchi J, Ringer DP, Takami Y, Nakayama T, Suiko M, and Liu M-C (1998) Molecular cloning, expression, and characterization of novel human SULT1C sulfotransferases that catalyze the sulfonation of N-hydroxy-2-acetylaminofluorene. J Biol Chem 273:33929-33935.

Santa Cruz A, Meşe G, Valiuniene L, Brink PR, White TW, and Valiunas V (2015) Altered conductance and permeability of $\mathrm{Cx} 40$ mutations associated with atrial fibrillation. J Gen Physiol 146:387-398.

Santalucía T, Camps M, Castelló A, Muñoz P, Nuel A, Testar X, Palacin M, and Zorzano A (1992) Developmental regulation of GLUT-1 (erythroid/Hep G2) and GLUT-4 (muscle/fat) glucose transporter expression in rat heart, skeletal muscle, and brown adipose tissue. Endocrinology 130:837-846.

Santes-Palacios R, Ornelas-Ayala D, Cabañas N, Marroquín-Pérez A, Hernández-Magaña A, Del Rosario Olguín-Reyes S, Camacho-Carranza R, and Espinosa-Aguirre JJ (2016) Regulation of human cytochrome P4501A1 (hCYP1A1): a plausible target for chemoprevention? BioMed Res Int 2016:5341081.

Scheepers A, Schmidt S, Manolescu A, Cheeseman CI, Bell A, Zahn C, Joost HG, and Schürmann A (2005) Characterization of the human SLC2A11 (GLUT11) gene: alternative promoter usage, function, expression, and subcellular distribution of three isoforms, and lack of mouse orthologue. Mol Membr Biol 22:339-351.

Schramm M, Klieber HG, and Daut J (1994) The energy expenditure of actomyosin-ATPase, $\mathrm{Ca}(2+)-A T P a s e$ and $\mathrm{Na}+\mathrm{K}(+)-A T P a s e$ in guinea-pig cardiac ventricular muscle. $J$ Physiol 481: 647-662.

Schumacher T and Benndorf RA (2017) ABC transport proteins in cardiovascular disease-a brief summary. Molecules 22. DOI: 10.3390/molecules22040589.

Sekine T, Kusuhara H, Utsunomiya-Tate N, Tsuda M, Sugiyama Y, Kanai Y, and Endou H (1998) Molecular cloning and characterization of high-affinity carnitine transporter from rat intestine. Biochem Biophys Res Commun 251:586-591.

Severs NJ, Bruce AF, Dupont E, and Rothery S (2008) Remodelling of gap junctions and connexin expression in diseased myocardium. Cardiovasc Res 80:9-19.

Shoieb SM and El-Kadi AOS (2018) S-enantiomer of 19-hydroxyeicosatetraenoic acid preferentially protects against angiotensin II-induced cardiac hypertrophy. Drug Metab Dispos 46: $1157-1168$.

Silvestre J-S, Robert V, Heymes C, Aupetit-Faisant B, Mouas C, Moalic J-M, Swynghedauw B, and Delcayre C (1998) Myocardial production of aldosterone and corticosterone in the rat: physiological regulation. $J$ Biol Chem 273:4883-4891.

Singh SP, Schragenheim J, Cao J, Falck JR, Abraham NG, and Bellner L (2016) PGC-1 alpha regulates HO-1 expression, mitochondrial dynamics and biogenesis: role of epoxyeicosatrienoic acid. Prostaglandins Other Lipid Mediat 125:8-18.

Solanki M, Pointon A, Jones B, and Herbert K (2018) Cytochrome P450 2J2: potential role in drug metabolism and cardiotoxicity. Drug Metab Dispos 46:1053-1065.

Solbach TF, Grube M, Fromm MF, and Zolk O (2011) Organic cation transporter 3: expression in failing and nonfailing human heart and functional characterization. J Cardiovasc Pharmacol 58: 409-417.

Solbach TF, König J, Fromm MF, and Zolk O (2006) ATP-binding cassette transporters in the heart. Trends Cardiovasc Med 16:7-15.

Sosinsky GE, Boassa D, Dermietzel R, Duffy HS, Laird DW, MacVicar B, Naus CC, Penuela S, Scemes E, Spray DC, et al. (2011) Pannexin channels are not gap junction hemichannels. Channels (Austin) 5:193-197.

Spiecker M, Darius H, Hankeln T, Soufi M, Sattler AM, Schaefer JR, Node K, Börgel J, Mügge A, Lindpaintner K, et al. (2004) Risk of coronary artery disease associated with polymorphism of the cytochrome P450 epoxygenase CYP2J2. Circulation 110:2132-2136.

Sridharan M, Adderley SP, Bowles EA, Egan TM, Stephenson AH, Ellsworth ML, and Sprague RS (2010) Pannexin 1 is the conduit for low oxygen tension-induced ATP release from human erythrocytes. Am J Physiol Heart Circ Physiol 299:H1146-H1152.

Srinivas SR, Prasad PD, Umapathy NS, Ganapathy V, and Shekhawat PS (2007) Transport of butyryl-L-carnitine, a potential prodrug, via the carnitine transporter OCTN2 and the amino acid transporter ATB $(0,+)$. Am J Physiol Gastrointest Liver Physiol 293:G1046-G1053.

Stanley WC, Hall JL, Smith KR, Cartee GD, Hacker TA, and Wisneski JA (1994) Myocardial glucose transporters and glycolytic metabolism during ischemia in hyperglycemic diabetic swine. Metabolism 43:61-69.

Stanley WC, Recchia FA, and Lopaschuk GD (2005) Myocardial substrate metabolism in the normal and failing heart. Physiol Rev 85:1093-1129.

Stegeman JJ, Woodin BR, Klotz AV, Wolke RE, and Orme-Johnson NR (1982) Cytochrome P-450 and monooxygenase activity in cardiac microsomes from the fish Stenotomus chrysops. Mol Pharmacol 21:517-526.
Sutherland L, Ebner T, and Burchell B (1993) The expression of UDP-glucuronosyltransferases of the UGT1 family in human liver and kidney and in response to drugs. Biochem Pharmacol 45: 295-301.

Szablewski L (2017) Glucose transporters in healthy heart and in cardiac disease. Int J Cardiol 230: $70-75$.

Takeda Y, Yoneda T, Demura M, Miyamori I, and Mabuchi H (2000) Cardiac aldosterone production in genetically hypertensive rats. Hypertension 36:495-500.

Tamai I, Nezu J, Uchino H, Sai Y, Oku A, Shimane M, and Tsuji A (2000) Molecular identification and characterization of novel members of the human organic anion transporter (OATP) family. Biochem Biophys Res Commun 273:251-260.

Tamai I, Ohashi R, Nezu J, Yabuuchi H, Oku A, Shimane M, Sai Y, and Tsuji A (1998) Molecular and functional identification of sodium ion-dependent, high affinity human carnitine transporter OCTN2. J Biol Chem 273:20378-20382.

Terao M, Romão MJ, Leimkühler S, Bolis M, Fratelli M, Coelho C, Santos-Silva T, and Garattini E (2016) Structure and function of mammalian aldehyde oxidases. Arch Toxicol 90:753-780.

Thum T and Borlak J (2000) Cytochrome P450 mono-oxygenase gene expression and protein activity in cultures of adult cardiomyocytes of the rat. Br J Pharmacol 130:1745-1752.

Trepanier LA, Ray K, Winand NJ, Spielberg SP, and Cribb AE (1997) Cytosolic arylamine $\mathrm{N}$-acetyltransferase (NAT) deficiency in the dog and other canids due to an absence of NAT genes. Biochem Pharmacol 54:73-80.

Tuomainen T and Tavi P (2017) The role of cardiac energy metabolism in cardiac hypertrophy and failure. Exp Cell Res 360:12-18.

Turk E, Zabel B, Mundlos S, Dyer J, and Wright EM (1991) Glucose/galactose malabsorption caused by a defect in the Nat/glucose cotransporter. Nature 350:354-356.

Tylutki Z and Polak S (2015) Plasma vs heart tissue concentration in humans - literature data analysis of drugs distribution. Biopharm Drug Dispos 36:337-351.

Uno Y, Murayama N, and Yamazaki H (2018) Molecular and functional characterization of $\mathrm{N}$-acetyltransferases NAT1 and NAT2 in cynomolgus macaque. Chem Res Toxicol 31: $1269-1276$.

Vandenbroucke E, Mehta D, Minshall R, and Malik AB (2008) Regulation of endothelial junctional permeability. Ann N Y Acad Sci 1123:134-145.

Van Kempen MJ, Vermeulen JL, Moorman AF, Gros D, Paul DL, and Lamers WH (1996) Developmental changes of connexin 40 and connexin 43 mRNA distribution patterns in the rat heart. Cardiovasc Res 32:886-900.

Van Poucke M, Melkebeek V, Erkens T, Van Zeveren A, Cox E, and Peelman LJ (2009) Molecular cloning and characterization of the porcine prostaglandin transporter (SLCO2A1): evaluation of its role in F4 mediated neonatal diarrhoea. BMC Genet 10:64.

Verhaagh S, Schweifer N, Barlow DP, and Zwart R (1999) Cloning of the mouse and human solute carrier 22a3 (Slc22a3/SLC22A3) identifies a conserved cluster of three organic cation transporters on mouse chromosome 17 and human 6q26-q27. Genomics 55:209-218.

Verheule S and Kaese S (2013) Connexin diversity in the heart: insights from transgenic mouse models. Front Pharmacol 4:81.

Vermij SH, Abriel H, and van Veen TAB (2017) Refining the molecular organization of the cardiac intercalated disc. Cardiovasc Res 113:259-275.

Visonà SD, Benati D, Monti MC, Galiè M, Andrello L, Frontini A, and Osculati A (2018) Diagnosis of sudden cardiac death due to early myocardial ischemia: an ultrastructural and immunohistochemical study. Eur J Histochem 62:2866.

Visscher H, Rassekh SR, Sandor GS, Caron HN, van Dalen EC, Kremer LC, van der Pal HJ, Rogers PC, Rieder MJ, Carleton BC, et al.; CPNDS consortium (2015) Genetic variants in SLC22A17 and SLC22A7 are associated with anthracycline-induced cardiotoxicity in children. Pharmacogenomics 16:1065-1076.

Vreeker A, van Stuijvenberg L, Hund TJ, Mohler PJ, Nikkels PGJ, and van Veen TAB (2014) Assembly of the cardiac intercalated disk during pre- and postnatal development of the human heart. PLoS One 9:e94722.

Waller AP, George M, Kalyanasundaram A, Kang C, Periasamy M, Hu K, and Lacombe VA (2013) GLUT12 functions as a basal and insulin-independent glucose transporter in the heart. Biochim Biophys Acta 1832:121-127.

Walraven JM, Barker DF, Doll MA, and Hein DW (2007) Tissue expression and genomic sequences of rat $\mathrm{N}$-acetyltransferases $r N a t 1, r N a t 2, r N a t 3$, and Functional characterization of a novel $r N a t 3 * 2$ genetic variant. Toxicol Sci 99:413-421.

Wang C and Hu S-M (1991) Developmental regulation in the expression of rat heart glucose transporters. Biochem Biophys Res Commun 177:1095-1100.

Wang JF, Yang Y, Sullivan MF, Min J, Cai J, Zeldin DC, Xiao YF, and Morgan JP (2002) Induction of cardiac cytochrome p450 in cocaine-treated mice. Exp Biol Med (Maywood) 227: $182-188$.

Ware B, Bevier M, Nishijima Y, Rogers S, Carnes CA, and Lacombe VA (2011) Chronic heart failure selectively induces regional heterogeneity of insulin-responsive glucose transporters. $\mathrm{Am}$ J Physiol Regul Integr Comp Physiol 301:R1300-R1306.

Waxse BJ, Sengupta P, Hesketh GG, Lippincott-Schwartz J, and Buss F (2017) Myosin VI facilitates connexin 43 gap junction accretion. $J$ Cell Sci 130:827-840.

Westphal K, Weinbrenner A, Giessmann T, Stuhr M, Franke G, Zschiesche M, Oertel R, Terhaag B, Kroemer HK, and Siegmund W (2000) Oral bioavailability of digoxin is enhanced by talinolol: evidence for involvement of intestinal P-glycoprotein. Clin Pharmacol Ther 68:6-12.

Wu S, Chen W, Murphy E, Gabel S, Tomer KB, Foley J, Steenbergen C, Falck JR, Moomaw CR, and Zeldin DC (1997) Molecular cloning, expression, and functional significance of a cytochrome P450 highly expressed in rat heart myocytes. J Biol Chem 272:12551-12559.

Wu X, George RL, Huang W, Wang H, Conway SJ, Leibach FH, and Ganapathy V (2000) Structural and functional characteristics and tissue distribution pattern of rat OCTN1, an organic cation transporter, cloned from placenta. Biochim Biophys Acta 1466:315-327.

Yabuuchi H, Tamai I, Nezu J, Sakamoto K, Oku A, Shimane M, Sai Y, and Tsuji A (1999) Novel membrane transporter OCTN1 mediates multispecific, bidirectional, and $\mathrm{pH}$-dependent transport of organic cations. J Pharmacol Exp Ther 289:768-773.

Yamanaka H, Nakajima M, Katoh M, and Yokoi T (2007) Glucuronidation of thyroxine in human liver, jejunum, and kidney microsomes. Drug Metab Dispos 35:1642-1648.

Yoon N, Dang TQ, Chasiotis H, Kelly SP, and Sweeney G (2014) Altered transendothelial transport of hormones as a contributor to diabetes. Diabetes Metab J 38:92-99.

Young LH, Renfu Y, Russell R, Hu X, Caplan M, Ren J, Shulman GI, and Sinusas AJ (1997) Lowflow ischemia leads to translocation of canine heart GLUT-4 and GLUT-1 glucose transporters to the sarcolemma in vivo. Circulation 95:415-422. 
Zhang F, Bian Y, Huang L, and Fan W (2017) Association between connexin 40 and potassium voltage-gated channel subfamily A member 5 expression in the atrial myocytes of patients with atrial fibrillation. Exp Ther Med 14:5170-5176

Zhang Y, El-Sikhry H, Chaudhary KR, Batchu SN, Shayeganpour A, Jukar TO, Bradbury JA, Graves JP, DeGraff LM, Myers P, et al. (2009) Overexpression of CYP2J2 provides protection against doxorubicin-induced cardiotoxicity. Am J Physiol Heart Circ Physiol 297: H37-H46.

Zhou L, Cryan EV, D’Andrea MR, Belkowski S, Conway BR, and Demarest KT (2003) Human cardiomyocytes express high level of Na+/glucose cotransporter 1 (SGLT1). J Cell Biochem 90: 339-346.

Zhou ZY, Wan LL, Yang QJ, Han YL, Li D, Lu J, and Guo C (2016) Nilotinib reverses ABCB1/Pglycoprotein-mediated multidrug resistance but increases cardiotoxicity of doxorubicin in a MDR xenograft model. Toxicol Lett 259:124-132.

Zordoky BN and El-Kadi AO (2008) Modulation of cardiac and hepatic cytochrome P450 enzymes during heart failure. Curr Drug Metab 9:122-128.

Zordoky BNM, Aboutabl ME, and El-Kadi AOS (2008) Modulation of cytochrome P450 gene expression and arachidonic acid metabolism during isoproterenol-induced cardiac hypertrophy in rats. Drug Metab Dispos 36:2277-2286.
Zwart R, Verhaagh S, Buitelaar M, Popp-Snijders C, and Barlow DP (2001) Impaired activity of the extraneuronal monoamine transporter system known as uptake-2 in Orct3/Slc22a3-deficient mice. Mol Cell Biol 21:4188-4196.

Address correspondence to: Elizabeth A. Hausner, Division of Cardiovascular and Renal Products, Center for Drug Evaluation and Research, United States Food and Drug Administration, White Oak, Building 22/Room 4168, 10903 New Hampshire Avenue, Silver Spring, MD 20993. E-mail: Elizabeth.Hausner@fda.hhs.gov; or Susan A. Elmore, Toxicologic Pathologist, National Toxicology Program, National Institute of Environmental Sciences, 111 TW Alexander Drive, RTP, NC 27709. E-mail: Elmore@niehs.nih.gov; or Dr. Xi Yang, Division of Cardiovascular and Renal Products CDER/FDA White Oak, BIdg 22/ Room 4175, 10903 New Hampshire Avenue, Silver Spring, MD 20993. E-mail: Xi.Yang@fda.hhs.gov 